
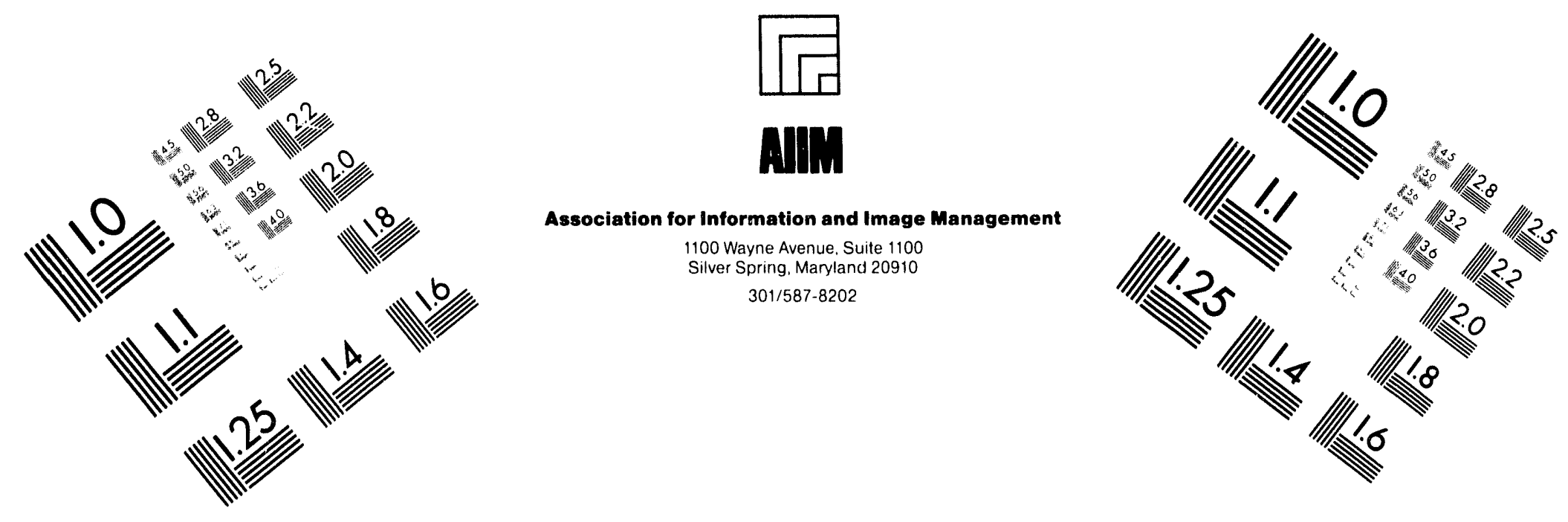

\title{
Centimeter
}

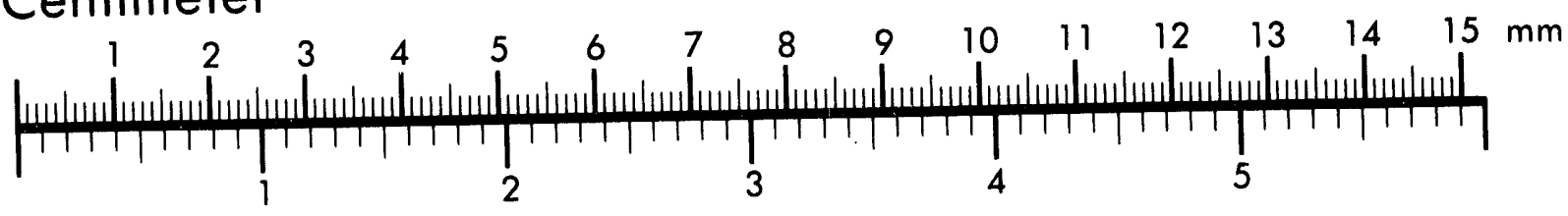
Inches
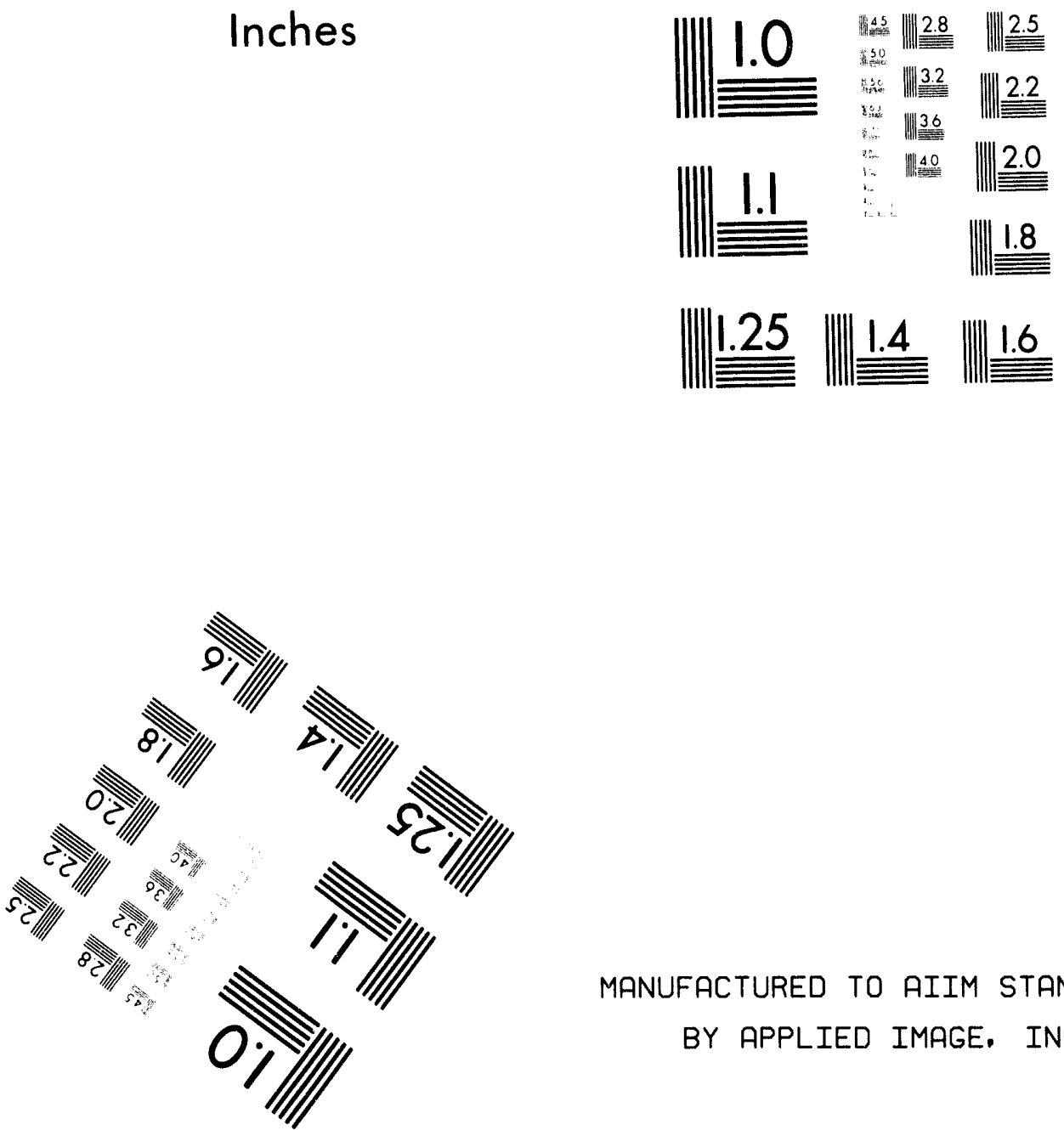

MANUFACTURED TO AIIM STANDARDS

BY APPLIED IMAGE. INC.

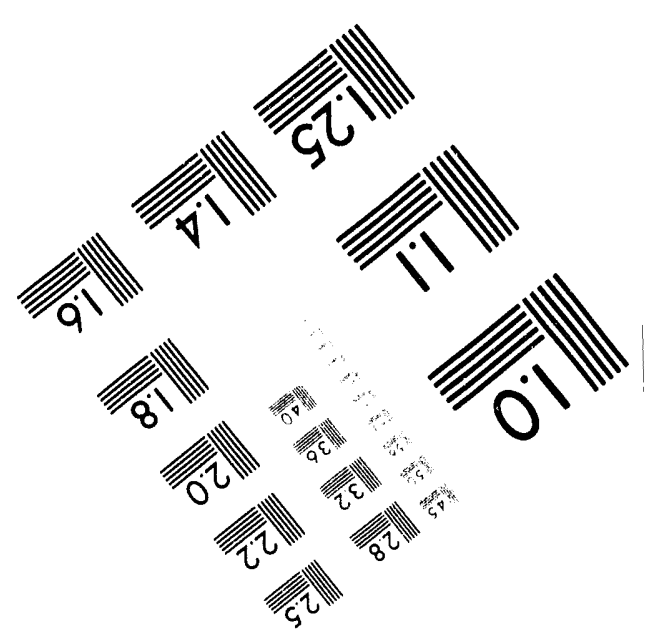



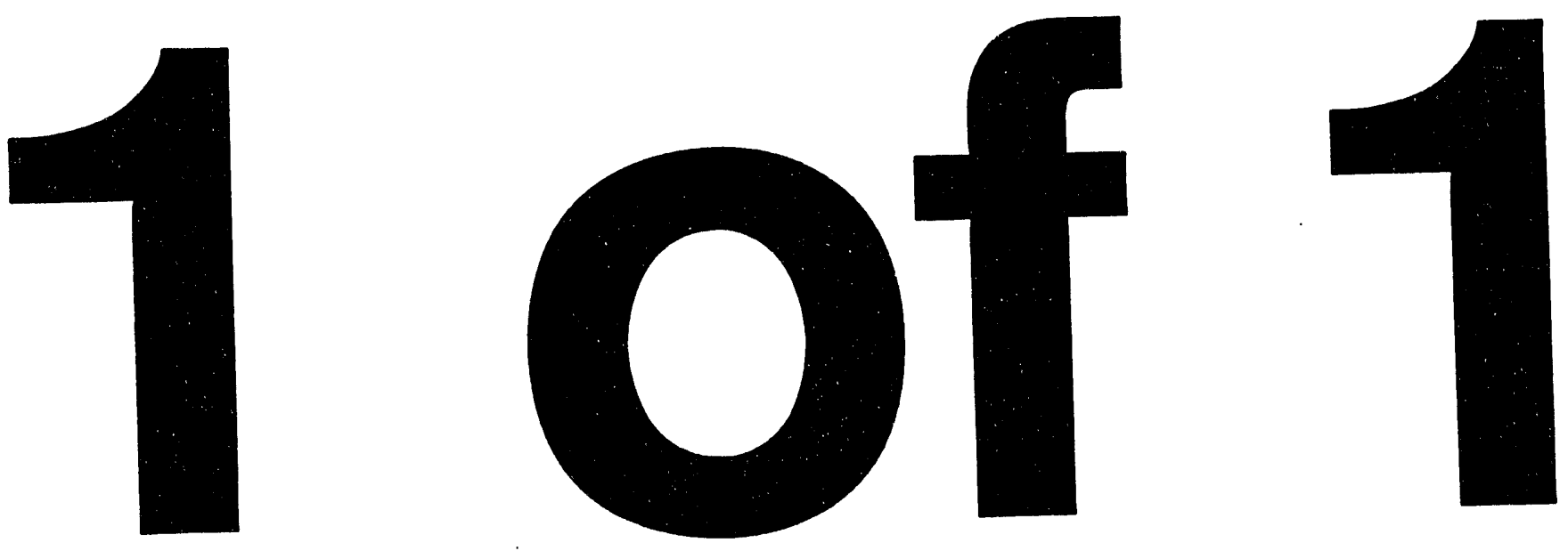
NUREG/CR-5919

CNWRA 92-007

\section{Repository Operational Criteria Comparative Analysis}

Manuscript Completed: May 1994

Date Published: June 1994

Prepared by

J. P. Hageman, A. H. Chowdhury

Center for Nuclear Waste Regulatory Analyses

Southwest Research Institute

6220 Culebra Road

San Antonio, TX 78238-5166

\section{Prepared for}

Division of Waste Management

Office of Nuclear Material Safety and Safeguards

U.S. Nuclear Regulatory Commission

Washington, DC 20555-0001

NRC FIN D1035 


\begin{abstract}
The objective of the "Repository Operational Criteria (ROC) Feasibility Studies" (or ROC task) was to conduct comprehensive and integrated analyses of repository design, construction, and operations criteria in 10 CFR Part 60 regulations considering the interfaces among the components of the regulations and impacts of any potential changes to those regulations. The ROC task addresses regulatory criteria and uncertainties related to the preclosure aspects of the geologic repository. Those parts of 10 CFR Part 60 that require routine guidance or minor changes to the rule were addressed in Hageman and Chowdhury, 1992. The ROC task shows a possible need for further regulatory clarity, by major changes to the rule, related to the design bases and siting of a geologic repository operations area and radiological emergency planning in order to assure defense-in-depth. The analyses, presented in this report, resulted in the development and refinement of regulatory concepts and their supporting rationale for recommendations for potential major changes to 10 CFR Part 60 regulations.
\end{abstract}




\section{CONTENTS}

Section Page

EXECUTIVE SUMMARY $\ldots \ldots \ldots \ldots \ldots \ldots \ldots \ldots \ldots \ldots \ldots \ldots$ ix

ACKNOWLEDGEMENTS $\ldots \ldots \ldots \ldots \ldots \ldots \ldots \ldots \ldots \ldots \ldots \ldots \ldots$

ACRONYMS $\ldots \ldots \ldots \ldots \ldots \ldots \ldots \ldots \ldots \ldots \ldots \ldots \ldots \ldots \ldots \ldots \ldots \ldots \ldots$

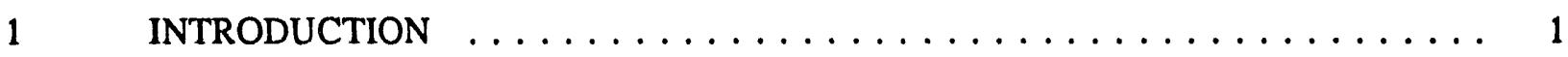

1.1 PURPOSE AND SCOPE OF THI REPORT $\ldots \ldots \ldots \ldots \ldots \ldots \ldots \ldots \ldots$

1.2 GENERAL DISCUSSION OF THE REPOSITORY OPERATIONAL CRITERIA (ROC) FEASIBILITY STUDIES $\ldots \ldots \ldots \ldots \ldots \ldots \ldots \ldots \ldots \ldots \ldots \ldots \ldots \ldots \ldots$

2 SPECIFIC TECHNICAL AND REGULATORY TOPICS $\ldots \ldots \ldots \ldots \ldots \ldots$

2.1 PERFORMANCE OBJECTIVES $\ldots \ldots \ldots \ldots \ldots \ldots \ldots \ldots \ldots \ldots \ldots$

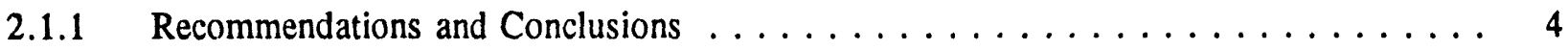

2.1.1.1 Protection Against Radiation - GROA $\ldots \ldots \ldots \ldots \ldots \ldots \ldots \ldots \ldots \ldots$

2.1.1.2 Protection Against Radiation - Important to Safety and Siting . . . . . . . . . . . 4

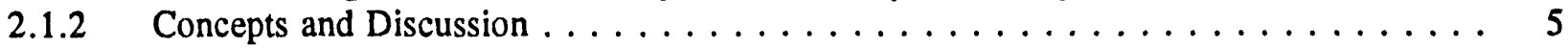

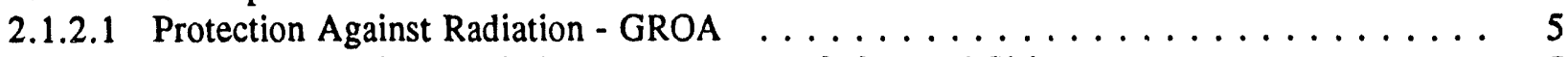

2.1.2.2 Protection Against Radiation - Important to Safety and Siting . . . . . . . . . . . 5

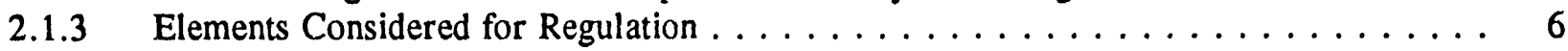

2.1.3.1 Protection Against Radiation - GROA $\ldots \ldots \ldots \ldots \ldots \ldots \ldots$

2.1.3.2 Protection Against Radiation - Important to Safety and Siting . . . . . . . . . . . 7

2.1 .4 Safety Functions and Regulatory Citations . . . . . . . . . . . . . . 8

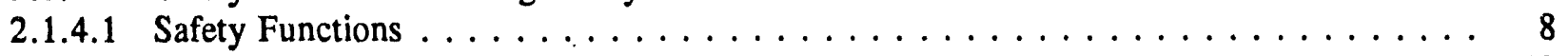

2.1.4.2 Relevant Regulatory Citations $\ldots \ldots \ldots \ldots \ldots \ldots \ldots \ldots \ldots \ldots \ldots$

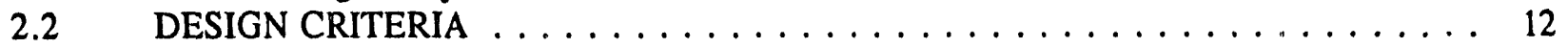

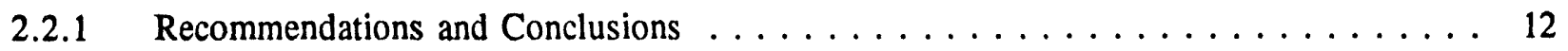

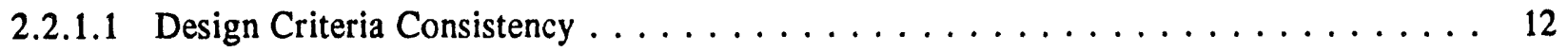

2.2.1.2 Radiation Protection $\ldots \ldots \ldots \ldots \ldots \ldots \ldots \ldots \ldots \ldots \ldots \ldots \ldots \ldots$

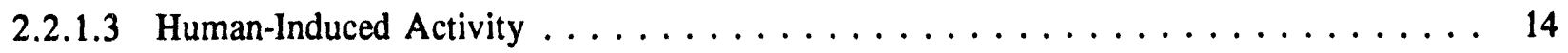

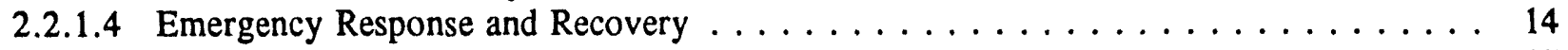

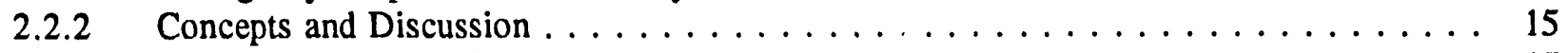

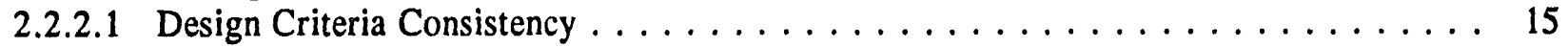

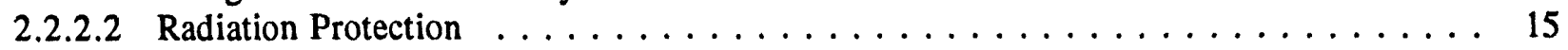

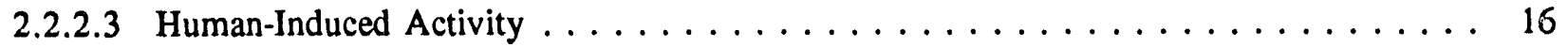

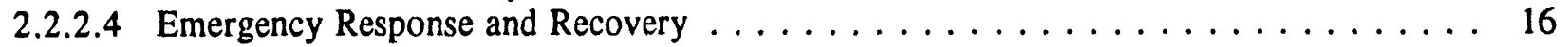

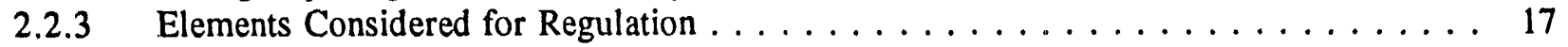

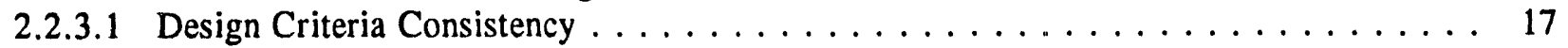

2.2.3.2 Radiation Protection $\ldots \ldots \ldots \ldots \ldots \ldots \ldots \ldots \ldots \ldots \ldots \ldots$

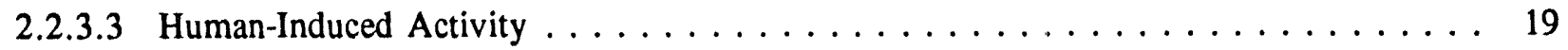

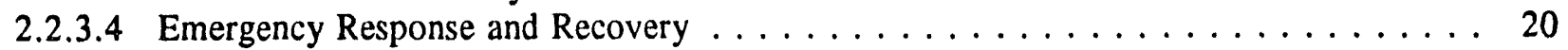

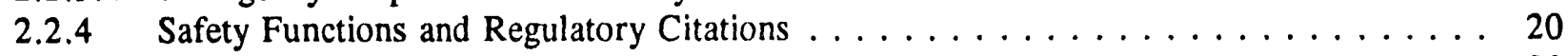

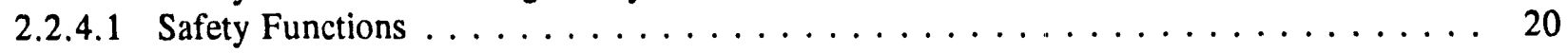




\section{CONTENTS (Cont'd)}

Section

Page

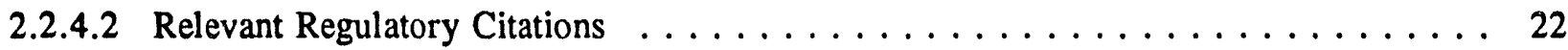

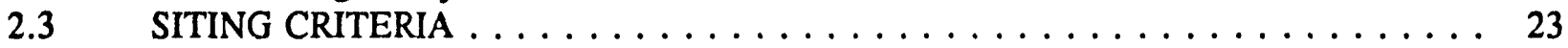

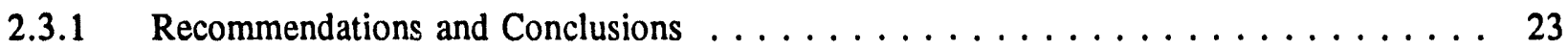

2.3.1.1 Establish a Preclosure Controlled Area and Individual Dose . . . . . . . . . . . 23

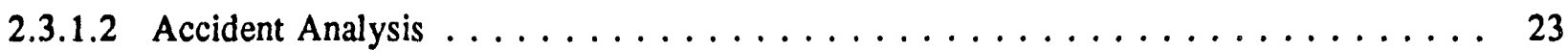

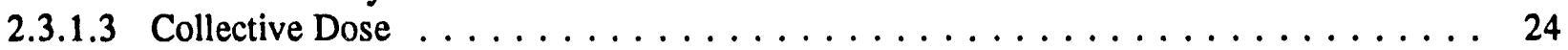

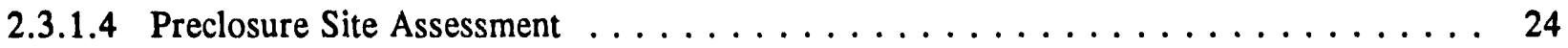

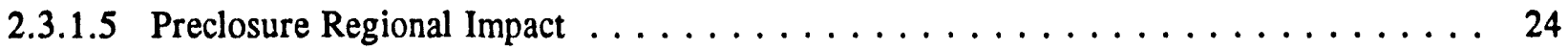

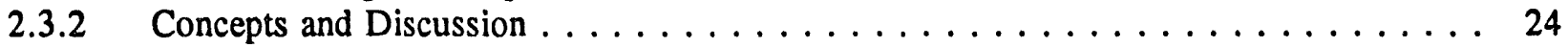

2.3.2.1 Establish a Preclosure Controlled Area and Individual Dose . . . . . . . . . . . 24

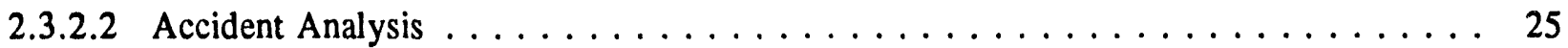

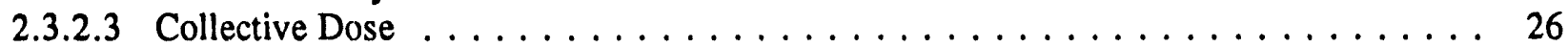

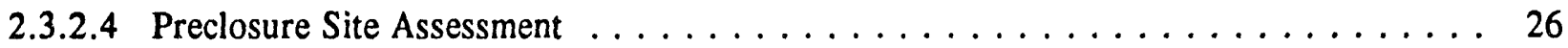

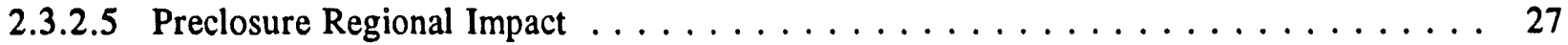

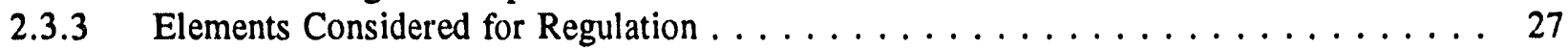

2.3.3.1 Establish a Preclosure Controlled Area and Individual Dose . . . . . . . . . . 27

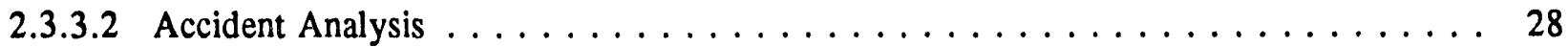

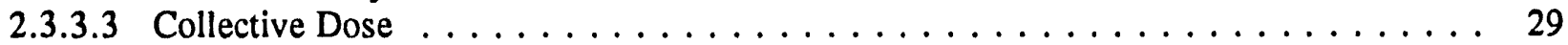

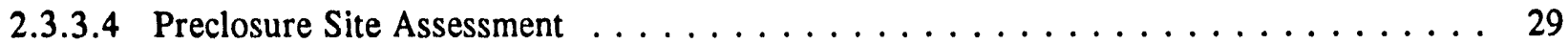

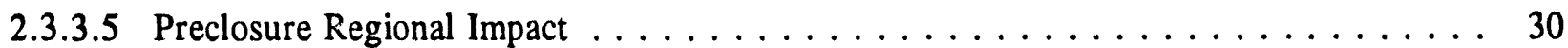

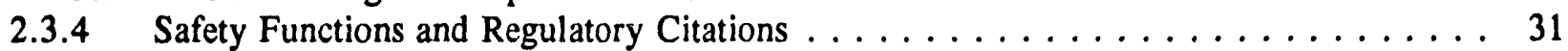

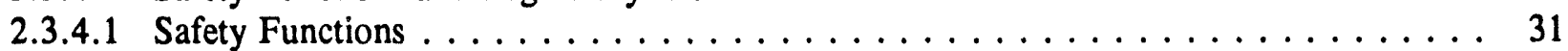

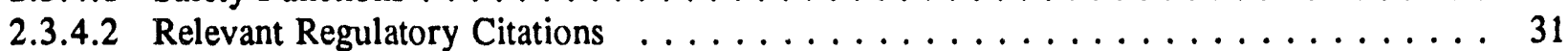

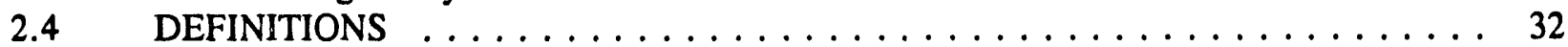

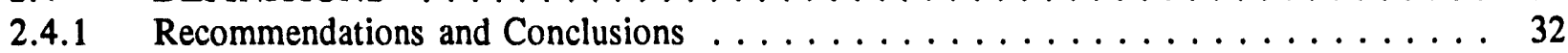

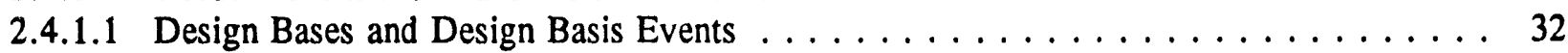

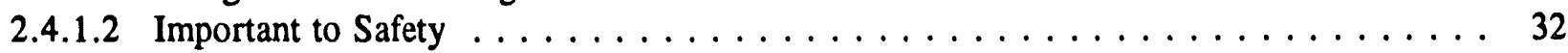

2.4.1.3 Controlled Area or Controlled-use Area $\ldots \ldots \ldots \ldots \ldots \ldots \ldots \ldots$

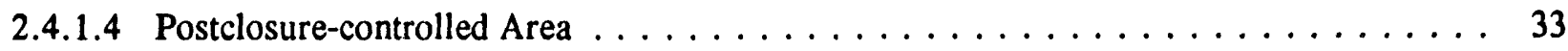

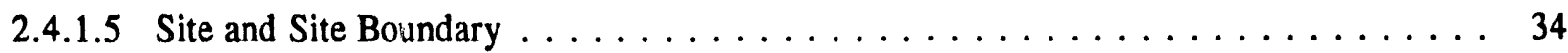

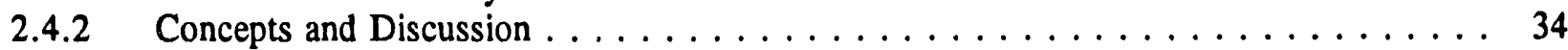

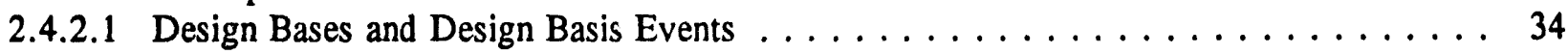

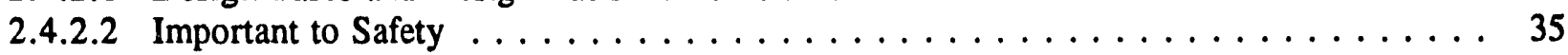

2.4.2.3 Controlled Area or Controlled-use Area $\ldots \ldots \ldots \ldots \ldots \ldots \ldots \ldots$

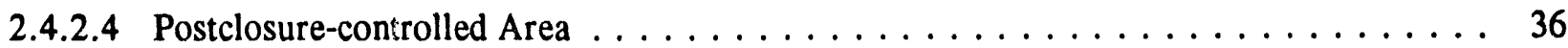

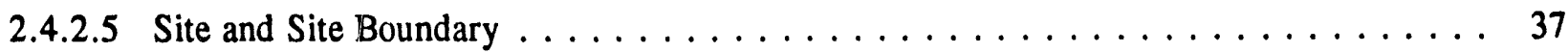

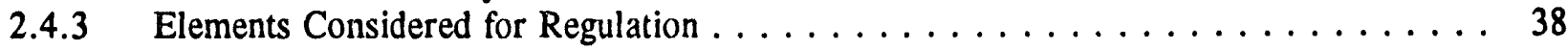

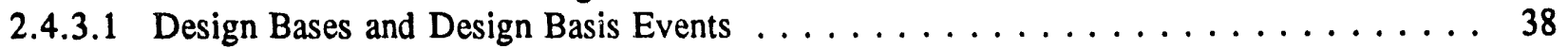

2.4.3.2 Important to Safety . . . . . . . . . . . . . . . . . . . . . 39

2.4.3.3 Controlled Area or Controlled-use Area $\ldots \ldots \ldots \ldots \ldots \ldots \ldots \ldots \ldots$

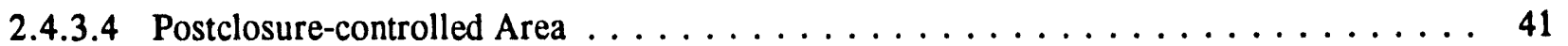

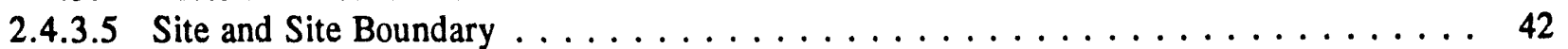




\section{CONTENTS (Cont'd)}

Section

Page

2.4.4 Safety Functions and Regulatory Citations $\ldots \ldots \ldots \ldots \ldots \ldots \ldots$

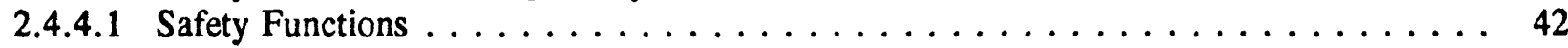

2.4.4.2 Relevant Regulatory Citations $\ldots \ldots \ldots \ldots \ldots \ldots \ldots \ldots \ldots \ldots \ldots$

2.5 RADIOLOGICAL EMERGENCY PLANNING $\ldots \ldots \ldots \ldots \ldots \ldots \ldots \ldots \ldots$

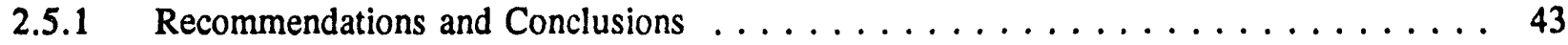

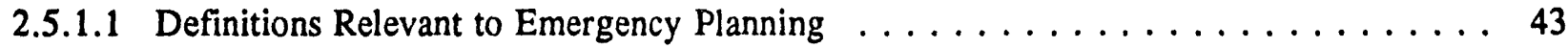

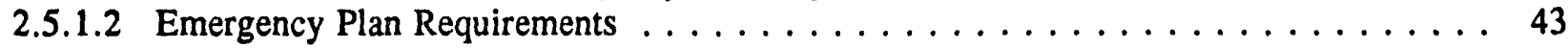

2.5.1.3 Offsite Organization Comments $\ldots \ldots \ldots \ldots \ldots \ldots \ldots \ldots \ldots \ldots$

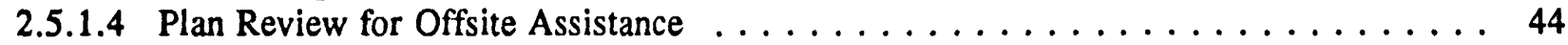

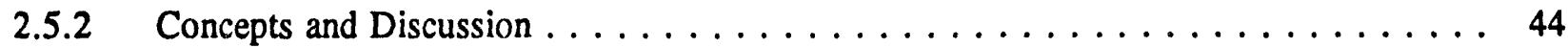

2.5.2.1 Definitions Relevant to Emergency Planning . . . . . . . . . . . . . . . . 44

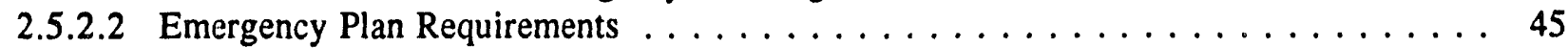

2.5.2.3 Offsite Organization Comments $\ldots \ldots \ldots \ldots \ldots \ldots \ldots \ldots \ldots$

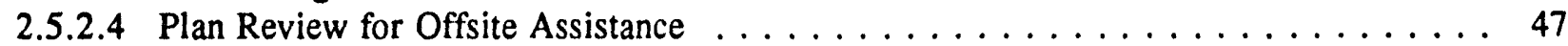

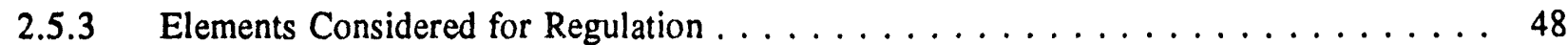

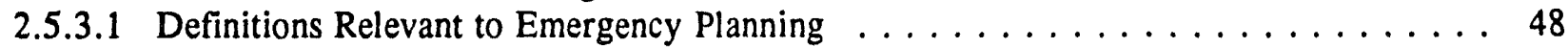

2.5.3.2 Emergency Plan Requirements . . . . . . . . . . . . . . . . . . . . . 48

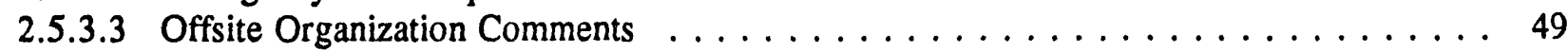

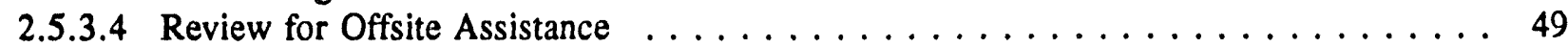

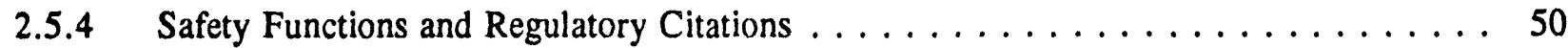

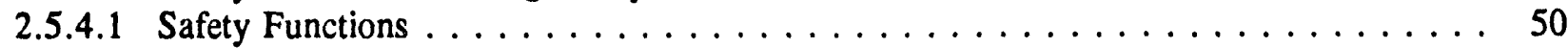

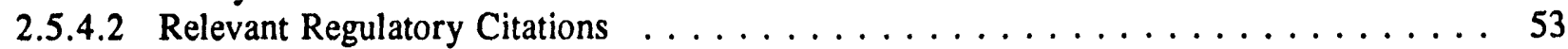

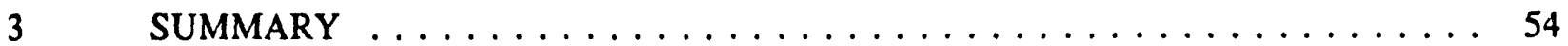

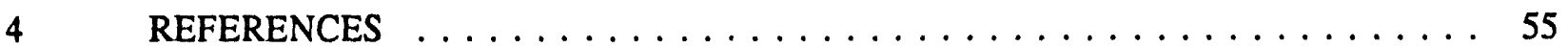




\section{EXECUTIVE SUMMARY}

This report covers the work accomplished during Activity 3 of the Center for Nuclear Waste Regulatory Analyses task entitled "Repository Operational Criteria (ROC) Feasibility Studies." The objective of the ROC task was to conduct comprehensive and integrated analyses of repository design, construction, and operations regulations in Title 10 of the Code of Federal Regulations (CFR), Part 60, "Disposal of High-Level Radioactive Wastes in Geologic Repositories," (10 CFR Part 60). The ROC task was to consider among the components of the regulations the interfaces and impacts of any potential changes to the regulations. The scope of the ROC task was to address regulatory uncertainties related to the preclosure aspects of the geologic repository, including the design bases of a geologic repository operations area (GROA) and the design and planning considerations for radiation accidents.

The ROC task was designed to be comprehensive and integrated. Comprehensiveness was achieved by compiling a complete list of ROC Topics for analysis. A ROC Topic is a specific subject area of analysis identified from several subject areas associated with the regulations of repository design, construction, and operations. A key feature of the approach was to present regulatory concepts or potential repository operational criteria (PROC) in a manner to permit integration of various aspects among several ROC Topics. PROC were presented in an earlier ROC task report and only regulatory concepts are presented in this report. The integration of all the criteria (current and potential) was essential. If criteria were suggested (such as a different definition of the term "important to safety" or potential radiation accident siting or planning criteria), the impacts of such suggestions were addressed in each applicable ROC Topic.

During Activity 1 a group of selected technical and regulatory analysts developed a preliminary list of ROC Topics, which was then compared to several regulations (10 CFR Parts 2, 20, 50, 51, 60, 72, and 100 , and 30 CFR Part 57) relevant to geologic repository operations as a check of the comprehensiveness of the list. This approach was used to assure that the list was comprehensive (covering all aspects relevant to geologic repository operational criteria). These ROC Topics were then expanded and subdivided by identification of their elements. Each ROC Topic was analyzed to develop regulatory concepts which were used to assess the adequacy and sufficiency of the current operational criteria. During Activity 2, the ROC Topics were reviewed, commented on, and categorized by technical significance and, thus, the need for further analysis. These reviews and comments resulted in $43 \mathrm{ROC}$ Topics, which were then grouped into four categories: (i) Category 1 - Routine Guidance, (ii) Category 2 - Specific Guidance, (iii) Category 3 - Minor Change to the Rule (Category 1, 2, and 3 required no further ROC task action), and (iv) Category 4 - Potential Major Change to the Rule.

The results of Activities 1 and 2 (Hageman and Chowdhury, 1992) indicate that the current criteria in 10 CFR Part 60 may require regulatory clarification regarding the five ROC Topics that are in Category 4. These five topics are related to the design bases for the GROA, preclosure siting, and radiological emergency planning to assure defense-in-depth.

A comparative analysis of (i) the current regulations in 10 CFR Part 60, (ii) the concepts developed in Activities 1 and 2, and (iii) other applicable regulations, such as 10 CFR Parts 50, 72, and 100 was then conducted in Activity 3. This comparative analysis resulted in the refinement of the concepts and their supporting rationale for recommendations for potential changes to 10 CFR Part 60 . Four of these five 
ROC Topics are related to the Nuclear Regulatory Commission (NRC) Design Basis Events (DBEs) rulemaking, and the remaining one is related to the planned NRC Radiological Emergency Planning rulemaking.

The specific recommendations and conclusions reached by the ROC task are:

- The intent regarding the performance objectives for radiation safety may need to be clarified

- The intent of the performance of structures, systems, and components important to safety and the preclosure performance of the site may need to be clarified to assure defense-indepth

- Consistent terminology for the various classes of DBEs should be utilized

- It is clear that 10 CFR Part 60 regulates concentrations of airborne radioactive material in restricted and unrestricted areas and that design for decontamination is not limited to decommissioning only

- Design considerations for human-induced events may need to be clarified

- The meaning of the term "emergency" in relation to "radiation accidents" may need to be clarified

- Criteria may be needed for establishment of a controlled area or controlled-use area for the preclosure period of the GROA

- A criterion requiring analysis of the potential effect of any DBE may be needed

- Criteria for collective dose limits in 10 CFR Part 60 are premature

- Current 10 CFR Part 60 criteria for preclosure site assessment are adequate

- The terms "design bases", "DBE," "controlled area" or "controlled-use area", "postclosure restricted area," "site" and "site boundary" may need to be added to or changed within 10 CFR Part 60 or made consistent with other regulations

- Criteria and definitions related to radiological emergency planning need to be added to 10 CFR Part 60. 


\section{ACKNOWLEDGEMENTS}

The authors and analysts wish to acknowledge the members of the Center for Nuclear Waste Regulatory Analyses technical and management staff (Wesley C. Patrick, Pat Mackin, and D. Ted Romine) for their technical review and comments on various sections of this report. The authors express their appreciation to the U.S. Nuclear Regulatory Commission management staff (Ronald L. Ballard, Banad N. Jagannath, and Mysore S. Nataraja) and the technical review team members (Phillip Altomare, Robert B. Neel, John S. Trapp, Rex G. Wescott, and James R. Wolf) for their assistance in development of this report. The authors also express their appreciation to the members of the secretarial staff (Jerriene Bishop and Cathy Garcia), and to the Southwest Research Institute Publications and Photography Services for helping prepare and edit this report. 


\title{
ACRONYMS
}

\author{
ANS - American Nuclear Society \\ ALARA - As low as is reasonably achievable \\ CFR - Code of Federal Regulations \\ CNWRA - Center for Nuclear Waste Regulatory Anal'ses \\ DBE - Design basis event \\ DOE - Department of Energy \\ EIS - Environmental Impact Statement \\ EPA - Environmental Protection Agency \\ GROA - Geologic repository operations area \\ HLW - High-level radioactive waste \\ ISFSI - Independent spent fuel storage installation \\ MRS - Monitored retrievable storage installation \\ NRC - Nuclear Regulatory Commission \\ PCD - Population center distance \\ PROC - Potential repository operational criteria \\ ROC - Repository operational criteria
}




\section{INTRODUCTION}

\subsection{PURPOSE AND SCOPE OF THIS REPORT}

This report presents the results of the technical effort performed for Activity 3 of the repository operational criteria (ROC) Feasibility Studies, hereinafter referred to as the ROC task. The scope of the effort for Activity 3 includes the following aspects.

- Comparison of Title 10 of the Code of Federal Regulations, Part 60, "Disposal of HighLevel Radioactive Wastes in Geologic Repositories," (10 CFR Part 60) to other relevant regulations, such as 10 CFR Parts 50,72, and 100, to lead to development of methods to address regulatory uncertainties for only those ROC Topics which may need further regulatory clarity through major changes to the rule, as identified in Activity 2. A ROC Topic is a specific subject area of analysis identified from several subject areas associated with the regulations of repository design, construction, and operations.

- Refinement of the concepts and rationale for potential major changes to the rule, developed in Activity 2, by comparison to other regulations.

Five ROC Topics were identified in Activity 2 as having potential for needing further regulatory clarity by a major change to the rule. Four of the five ROC Topics are related to the Nuclear Regulatory Commission (NRC) Design Basis Events (DBEs) rulemaking currently in progress, and the remaining one is related to the planned Radiological Emergency Planning rulemaking. This report presents the recommendations for the potential regulatory concepts for these two areas needing major changes to the rule and their supporting rationales.

\subsection{GENERAL DISCUSSION OF THE REPOSITORY OPERATIONAL CRITERIA (ROC) FEASIBILITY STUDIES}

Repository operational criteria deal with the design, construction, and operations of the High-Level Waste (HLW) geologic repository operations area (GROA) until permanent closure and license termination. This excludes aspects of post-permanent closure containment and isolation, but includes post-permanent closure surface facility decontamination or dismantlement and license termination. The ROC task has been conducted by the Center for Nuclear Waste Regulatory Analyses (CNWRA) to provide a systematic and comprehensive approach to determine the need for additional guidance or regulatory criteria development. The ROC task was conducted in three activities, and this report addresses the results of the third. Activities 1 and 2 (Hageman and Chowdhury, 1992) addressed those criteria where a major change to the rule was not required to reduce uncertainties, if any.

The ROC task addressed both repository operational safety functions and other areas such as definition of terms, preclosure site limitations, license amendment, and license termination. To provide a systematic method of analysis, it was necessary to build upon the CNWRA repository functional analysis (Romine, 1992) and develop a comprehensive list of topics within the scope of this task. The ROC Topic development process was performed by a group of analysts, who used their technical and regulatory experience to prepare a comprehensive list. The preliminary list of topics was then compared to several regulations (i.e., 10 CFR Parts 2, 20, 50, 51, 60, 72, and 100, and 30 CFR Part 57) as a check for any additional topics that could apply to the operation of a geologic repository. This approach 
helped to assure that the ROC Topics would be comprehensive (cover all aspects of the ROC task) and it checked for completeness by comparison to several regulations relevant to geologic repository operations.

An analysis of the ROC Topics was performed by comparing them to other relevant regulations and developing elements associated with each ROC Topic. This established the bases for regulatory concepts or potential repository operational criteria (PROC) for specific ROC Topics or subtopics. The regulatory concepts or PROC were compared to the current 10 CFR Part 60 to assess the relative sufficiency and adequacy. Sufficiency was determined if 10 CFR Part 60 addressed a needed regulatory concept. Adequacy was determined if 10 CFR Part 60 addressed a regulatory concept unambiguously. PROC were presented in an earlier report (Hageman and Chowdhury, 1992), but only regulatory concepts are presented in this report because of the significance of any potential major changes to the rule.

Each ROC Topic was reviewed, commented on, and categorized to identify and eliminate redundant or unnecessary items, resulting in 43 ROC Topics. The 43 ROC Topics were grouped into four categories:

- Category 1 - Routine Guidance The current regulatory criteria are adequate and sufficient to ensure safety, and no further ROC task analysis is required.

- Category 2 - Special Guidance The current regulatory criteria are adequate and sufficient to ensure safety, and a staff position may be desirable to provide additional guidance to assure compliance with a particular regulatory topic.

- Category 3 - Minor Change to the Rule The current regulatory criteria are adequate and sufficient to ensure safety, but a minor change to the rule may be desirable to clarify a specific item in the current criteria in order to remove any potential ambiguity.

- Category 4 - Potential Major Change to the Rule The current regulatory concepts may need to be clarified because the need for potential rulemaking has been documented by specific reservation in 10 CFR Part 60; a notice of proposed rulemaking has been issued; the need for rulemaking has been approved by the NRC Executive Director for Operations; or there is significant likelihood of not providing sufficient or adequate criteria to assure radiation safety, retrieval, containment, and isolation. Analysis, development, and documentation of a coordinated regulatory basis are determined to be necessary and beneficial for the current regulatory criteria. Items in this category are potential candidates for a major rulemaking.

Of the 43 ROC Topics, 26 were placed in Category 1 and were recommended to be addressed by routine guidance. It should be noted that even though no further ROC task actions are necessary, the background information and details for these ROC Topics will be useful for routine guidance documentation, such as in the planned NRC "Format and Content Regulatory Guide" and "License Application Review Plan." One ROC Topic was determined to be in Category 2 and may have a need for some guidance such as a technical or staff position. Eleven ROC Topics were in Category 3 and may have a need for minor changes to the rule. The ROC Topics placed in Categories 1, 2, and 3 do not require any further analysis (Hageman and Chowdhury, 1992). The five ROC Topics, which were determined to be in Category 4 - Potential Major Change to the Rule, are presented in Section 2 of this report. 


\section{SPECIFIC TECHNICAL AND REGULATORY TOPICS}

Five ROC Topics were identified which may require major changes to the rule to address the identified issues and concerns in a comprehensive and integrated manner. These ROC Topics with their associated subtopics are:

- Perfornance Objectives

- Protection Against Radiation - GROA

- Protection A-gainst Radiation - Important to Safety and Siting

- Design Criteria

- Design Criteria Consistency

- Radiation Protection

- Human-Induced Activity

- Emergency Response and Recovery

- Siting Criteria

- Establish a Preclosure Controlled Area and Individual Dose

- Accident Analysis

- Collective Dose

- Preclosure Site Assessment

- Preclosure Regional Impact

- Definitions

- Design Bases and Design Basis Events

- Important to Safety

- Controlled Area or Controlled-use Area

- Postclosure-controlled Area

- Site and Site Boundary

- Radiological Emergency Planning

- Definitions Relevant to Emergency Planning

- Emergency Plan Requirements

- Offsite Organization Comments

- Plan Review for Offsite Assistance

For each ROC Topic presented in Sections 2.1 to 2.5 below, four major subsections are presented in the following order:

- Recommendations and Conclusions

- Concepts and Discussions

- Elements Considered for Regulation

- Safety Functions and Regulatory Citations

Under each of these subsections the associated subtopics listed above are presented. This format emphasizes the results of Activity 3 by topic and places the supporting information for each topic as lower level material. 


\subsection{PERFORMANCE OBJECTIVES}

This ROC Topic has the following subtopics:

(1) Protection Against Radiation - GROA

(2) Protection Against Radiation - Important to Safety and Siting

\subsubsection{Recommendations and Conclusions}

\subsubsection{Protection Against Radiation - GROA}

\section{Recommendation}

The NRC intent regarding the performance objectives related to preclosure protection against radiation exposures and releases of radioactive material may need to be clarified.

\section{Conclusions}

The performance objectives for the GROA or their supporting documentation should clarify radiation safety requirements for all structures, systems, and components of the GROA. Performance objectives and design criteria should state what criteria are adequate to determine compliance (e.g., all structures, systems, and components in the GROA should be designed to meet the limits of 10 CFR Part 20). These criteria should be consistent with the defense-in-depth philosophy and specify the conditions and events :-nder which particular features must perform, as articulated in the Concept in Section 2.1.2.1, Prote tion Against Radiation - GROA.

\subsubsection{Protection Against Radiation - Important to Safety and Siting}

\section{Recommendation}

The NRC intent regarding the performance of structures, systems, and components important to safety and the preclosure performance of the site may need to be clarified.

\section{Conclusions}

The performance and functional safety requirements for structures, systems, and components important to safety should be clarified. Performance objectives or design criteria should indicate what criteria are adequate to determine compliance. For example, structures, systems, and components important to safety should perform their safety functions assuming occurrence of unlikely but credible events (i.e., those postulated events that are not expected to occur during the operational lifetime of the repository, but are sufficiently credible to warrant consideration). Items important to safety should prevent or mitigate damage to HLW assuming a DBE occurs. Also, the characteristics of the site should be such that the public will be protected from postulated radiation accidents during the operational period.

The performance objectives should be consistent with the defense-in-depth philosophy and specify the conditions under which particular features must perform, as articulated in the Concept in Section 2.1.2.2, Protection Against Radiation - Important to Safety and Siting. 


\subsubsection{Concepts and Discussion}

\subsubsection{Protection Against Radiation - GROA}

\section{Concept}

Structures, systems, and components of the GROA must be designed so that radiation exposures, radiation levels, and releases of radioactive materials will be maintained within the linits specified in 10 CFR Part 20 and such generally applicable environmental standards for rajioactivity as may have been established by the Environmental Protection Agency (EPA). The conditions under which these limits must be met include: regular events, frequently occurring events, and infrequent events expected to occur during the lifetime of the GROA.

\section{Discussion}

\section{CFR Part 60 Comparison}

The performance objective in 10 CFR 60.111(a) requires radiation exposures, levels and releases to the unrestricted area to meet the limits of 10 CFR Part 20 and any environmental standards established by the EPA. 10 CFR 60.111 (a) is explicitly silent regarding under what events or conditions this requirement must be met.

10 CFR 72.104 requires doses beyond the controlled area to meet the same limits given in $\mathbf{4 0}$ CFR Part 191, Subpart A, for normal operations and anticipated occurrences. In addition, there are operational restrictions to keep exposure as low as is reasonably achievable (ALARA). 10 CFR 50.34a requires that levels of radioactive materials in effluents to the unrestricted area be ALARA. The new 10 CFR Part 20 has ALARA criteria, and 10 CFR 60.111(a) and 60.131(a) have both referenced 10 CFR Part 20.

\section{Concept Comparison}

The Concept above is different from the concept explicitly contained in 10 CFR 60.111(a), however, it is similar to the concepts contained in 10 CFR Parts 50 and 72.

\subsubsection{Protection Against Radiation - Important to Safety and Siting}

\section{Concept}

Structures, systems, and components important to safety should be designed to perform their safety functions and to prevent and mitigate damage to HLW during and after the occurrence of unlikely but credible events (i.e., those events that are not expected to occur during the lifetime of the GROA, but are sufficiently credible to warrant consideration). Also, the GROA must be sited, designed, and operated to control the impact to radiological health and safety during and after the occurrence of a DBE, which may result in a radiation accident. 


\section{Discussion}

\section{CFR Part 60 Comparison}

10 CFR 60.111(a) requires that the GROA be designed so that the radiation control limits will not be exceeded during planned operations (at all times including retrieval). However, 10 CFR 60.111(a) is silent about when items important to safety must perform their necessary safety functions (i.e., under which classes of DBEs and conditions the necessary safety functions must be maintained). 10 CFR Part 60 requires that items important to safety have additional design criteria, beyond those for the remainder of the GROA to provide for defense-in-depth.

10 CFR Parts 50 and 72 account for accident conditions by providing guidelines for dose limits at the boundary of an exclusion area or controlled area. $10 \mathrm{CFR} 72.106(\mathrm{~b})$ requires that an individual located on or beyond the nearest boundary of the controlled area not receive a dose greater than 5 rems $(0.05 \mathrm{~Sv})$ to the whole body or any organ from a design basis accident. 10 CFR Part 60 contains no such text. In addition, 10 CFR 50.35 and 50.44(f) refer to 10 CFR Part 100 for the purposes of accident analysis and site selection. 10 CFR 100.11(a) contains language which is comparable to the concept in 10 CFR 72.106(b), but different dose values are used.

\section{Concept Comparison}

The Concept above is consistent with the concepts contained in 10 CFR Parts 50, 72, and 100.

\subsubsection{Elements Considered for Regulation}

\subsubsection{Protection Against Radiation - GROA}

\section{Elements Considered} radiation exposure are:

In order to protect the worker and the public, elements to be considered for protection against

- Dose limits for radiation workers

- Dose limits for members of the general population

- Limits on the concentration of radioactive material in air and water.

Elements of Design Events I, II, and III (NRC, 1989 and American Nuclear Society (ANS), 1984) would include:

- Normal operations

- Routine maintenance

- Anticipated operator errors (falling asleep, slow response to an alarm, illness)

- Anticipated natural phenomena (storms, winds, flash floods, seismic events)

- Anticipated environmental conditions (heat, humidity, cold). 


\section{Discussion of the Elements Considered}

10 CFR 60.111(a) addresses dose criteria for GROA facilities, but does not specify whether dose criteria apply under normal conditions or off-normal conditions and events. Difficulties arise when it is necessary to apply radiation dose criteria for potential radiation accidents. 10 CFR Part 60 covers the ALARA concept by a reference to 10 CFR Part 20, which does require ALARA. 10 CFR 60.132(c) and $60.133(\mathrm{~g})(1)$ address facility effluent control for normal operations and monitoring for any conditions.

\subsubsection{Protection Against Radiation - Important to Safety and Siting}

\section{Elements Considered} following:

Elements of Design Events I, II, and III (NRC, 1985 and ANS, 1984) would include the

- Normal operations

- Routine maintenance

- Expected operator errors (falling asleep, slow response to an alarm, illness)

- Expected natural phenomena (storms, winds, flash floods, seismic events)

- Expected environmental conditions (heat, humidity, cold, seismic shaking)

Elements of Design Events IV (NRC, 1989 and ANS, 1984) would include the following:

- Natural events that are credible but not expected to occur (large magnitude seismic events, floods, tornadoes)

- Human-induced events that are credible but not expected to occur (sabotage, equipment failure, power failure, operator death)

- Environmental conditions that are credible but not expected to occur

Elements beyond a Design Event IV (NRC, 1989 and ANS, 1984) would include the following:

- Design Events IV occurring simultaneously

- Improbable events

- Events that are not possible at a specific site (e.g., tsunami at Yucca Mountain)

Elements of the results of Design Events IV (NRC, 1989 and ANS, 1984) or beyond would include the following:

- Effluents above the limits of 10 CFR Part 20

- Exposures above the limits of 10 CFR Part 20

- Allowable levels of intake above the limits of 10 CFR Part 20

- Annual individual public exposures above the limits of 40 CFR Part 191, Subpart A

\section{Discussion of the Elements Considered}

Assumptions used herein include the concept that features (facilities, equipment, processes, etc.) which involve the use of any radioactive material are designed for Design Events I, II, and III (NRC, 1989 and ANS, 1984). Items important to safety are designed specifically to withstand Design Events 
I, II, III, and IV (NRC, 1989 and ANS, 1984). These items are not expected to withstand those events that are so improbable, due to their low probability of occurrence, as to not be considered in design. Those conditions and events that are never expected to occur during the operational life of the facility should have no consideration in designing the facility. Meteorite impacts, two low-probability events occurring simultaneously, airplane crashes (if specific air space traffic is forbidden), tsunamis more than 100 miles inland, or seismic events exceeding a site specific magnitude may be examples of such events.

The radiation protection limits in 10 CFK Part 20 and 40 CFR Part 191, Subpart A appear to apply to expected conditions and events for all features of the GROA. The NRC follows a defense-indepth philosophy which is intended to assure that an adequate level of protection can be maintained even if Design Events I through IV (NRC, 1989 and ANS, 1984) should occur. Radiation protection standards are contained in 10 CFR Part 20. These standards apply to operations at a geologic repository per 10 CFR 20.1002 and more specifically because 10 CFR 60.111(a) states in part: "Protection against radiation exposures and releases of radioactive material. The GROA shall be designed so that until permanent closure is completed, radiation exposures and radiation levels, and releases of radioactive materials to unrestricted areas, will at all times be maintained within the limits specified in Part 20 of this chapter...."

10 CFR 60.111(a) requires that releases and exposures will at all times be maintained within the limits of 10 CFR Part 20. The phrase "at all times" could be interpreted in two ways, i.e., (i) it could mean all periods of operations through permanent closure, or (ii) it could mean under all conditions and events (normal operctions and accident events). This is discussed in the excluded poteintial uncertainty on page B-34 to B-36 of Appendix B of Weiner, et al., 1990. Since time is more clearly associated with periods of operations, and only event frequency is time dependent, it is more logical to use the first interpretation. This interpretation is supported by pages 27 and 48 of NRC, 1983 where only time periods are mentioned. The NRC has explained that the phrase "at all times" was included to emphasize the need to design the GROA so that any waste retrieval found to be necessary in the future could be carried out in conformance with the radiation protection requirements of 10 CFR Part 20 (NRC, 1986).

\subsubsection{Safety Functions and Regulatory Citations}

\subsubsection{Safety Functions}

\section{Protection Against Radiation - GROA}

The safety functions (Romine, 1992) are:

Temporarily store waste disposal package components in lag (surge) storage during operations to prepare waste for disposal -5.5

Transfer waste during preparation operations (intra-facility) (see 6.5, Transfer waste (intra-facility) during repository operations) - 5.6

Process secondary waste for packaging (as required) - 5.8.3

Containerize secondary waste (if required) -5.8 .10$ 
Decontaminate waste disposal package surface areas during/following waste packaging (as required) - 5.8.11

Limit personnel radiation exposure during normal waste preparation operations - 5.16.1

Limit radiation level of waste contained in waste preparation operations - 5.16.2

Limit external radiation level of waste preparations operations - 5.16.3

Attenuate radiation from waste preparations operations $\mathbf{- 5 . 1 6 . 4}$

Limit personnel time and proximity to radiation sources $-\mathbf{5 . 1 6 . 5}$

Limit personnel radionuclide ingestion during waste preparations operations - 5.16.6

Decontaminate in event of release during waste praparation operations - 5.16.2.3 [sic] $(5.16 .7 .3)$

Limit planned radionuclide release rate during waste preparation operations -5.17 .1$

Monitor radionuclide releases during waste preparation operations - 5.17.1.1

Reduce radionuclide releases during waste preparation operations if excessive - 5.17.1.2

Minimize likelihood of accidental releases of radionuclides during waste preparaticn operations - 5.17 .2

Limit consequences of accidental radionuclide releases during waste preparation operations - 5.17 .3

Repository sewage collection, treatment, and disposal facilities and equipment - 5.35.1.3.7

Facility to prepare for disposal those secondary wastes generated during packaging of high-level waste - 5.35.5.1.6

Equipment for preparation of secondary waste for disposal - 5.35.5.2.9

Survey transportation package external dose rate upon receipt - 6.2.1.2

Temporarily store waste during repository operations - lag (surge) storage (if required) - 6.4

Install monitoring equipment for waste emplacement (as required) - 6.6.8

Continuously monitor radiation levels during repository operations - 6.8.1.1

Monitor environmental conditions to provide warning of potentially hazardous conditions or events during repository operations (e.g., air contamination, seismic event) - 6.8.1.2 
Continuously monitor personnel radiation exposure levels during repository operations - 6.8.1.3

Inspect, test and maintain monitoring facilities and equipment -6.8 .3$

Remove any/all waste from underground facility during repository waste handling operations (as required) -6.9

Survey waste disposal package external dose rate prior to removal from underground facility during waste removal operations - 6.9.9

Remove hazardous and potentially corrosive materials from the underground facility - 6.11.1.3

Install, calibrate and test subsurface postclosure monitoring equipment (as applicable) - 6.11.1.4

Examine performance capability of seals/backfills and monitoring equipment previously emplaced - 6.11.1.5

Repair/replace previously emplaced seals and/or backfill and monitoring equipment (as required) - 6.11.1.6

Limit personnel radiation exposure during waste disposal operations -6.16

Limit personnel radiation exposure during normal waste disposal operations - 6.16.1

Stop releases at the source (during waste disposal operations) - 6.16.2.1

Limit spread of contamination during waste disposal operations - 6.16.2.2

Decontaminate in event of release during waste disposal operations - 6.16.2.3

Limit planned radionuclide release rate during waste disposal operations - 6.17.1

Munitor radionuclide releases during waste disposal operations -6.17 .1 .1$

Reduce radionuclide releases during waste disposal operations if an unsafe condition exists - 6.17.1.2

Minimize likelihood of accidental releases of radionuclides during waste disposal operations -6.17 .2$

Limit radiation level in the unrestricted area due to waste preparation opeaaitions -6.18

Protect waste disposal package from damage during repository operations -6.20

Radiation-controlled repository facility for removing waste from transportation package - 6.41.2.1.5 
Radiation-controlled repository facility for waste inspection and test in receiving operations - 6.41.2.1.6

Ventilation and air conditioning for waste emplacement facilities (surface and subsurface) - 6.41.7.1.4

Limit radionuclide releases to the geologic setting (postclosure) -7.2

Limit initial radionuclide inventory - 7.2.1.1

Prevent migration of radionuclides to the geologic setting - 7.2.1.2

Control race of migration within the engineered barrier(s) (e.g., such that significant radionuclide decay occurs) -72.1 .3$

Limit rate of radionuclide release to the geologic setting -7.2 .2$

Limit gaseous radionuclide release rate(s) - 7.2.2.2

Limit migration rate within the engineered barrier(s) - 7.2.2.6

Limit releases of radionuclides to the accessible environment $-\mathbf{7 . 3}$

Ensure geologic environment that is not conducive to gaseous radionuclide transport - 7.3.8

Establish a controlled area -7.4 .1$

\section{Protection Against Radiation - Important to Safety and Siting}

The safety functions (Romine, 1992) are:

Decontaminate waste disposal package surface areas during/following waste packaging (as required) - 5.8.11

Limit personnel radiation exposure during preparation of waste for disposal - 5.16

Limit personnel radiation exposure during normal waste preparation operations -5.16 .1$

Limit spread of contamination during waste preparation operations -5.16 .2 .2 [sic] (5.16.7.2)

Limit spread of contamination in event of accidental release during waste preparation operations (if possible) - 5.17.3.2

Decontaminate in event of accidental release during waste preparation operations (if possible) - 5.17.3.3

Decontaminate transportation package/waste surface areas in receiving (if required) - 6.2.3 
Continuously monitor conditions that may impact personnel safety (radiological and non-radiological) during repository operations -6.8 .1$

Continuously monitor radiation levels during repository operations - 6.8.1.1

Monitor environmental conditions to provide warning of potentially hazardous conditions or events during repository operations (e.g., air contamination, seismic event) - 6.8.1.2

Continuously monitor personnel radiation exposure levels during repository operations -6.8 .1 .3$

Limit spread of contamination during waste disposal operations - 6.16.2.2

Limit spread of contamination in event of accidental release (if possible) - 6.17.3.2

\subsubsection{Relevant Regulatory Citations}

- 10 CFR 20.1002

- 10 CFR 50.34a, 50.35, and 50.44(f)

- 10 CFR 60.111(a), 60.132(c), 60.133(g)(1)

- 10 CFR 72.104, 72.106(b)

- 10 CFR 100.11(a)

- 40 CFR Part 191, Subpart A

\subsection{DESIGN CRITERIA}

This ROC Topic has the following subtopics:

(1) Design Criteria Consistency

(2) Radiation Protection

(3) Human-Induced Activity

(4) Emergency Response and Recovery

\subsubsection{Recommendations and Conclusions}

\subsubsection{Design Criteria Consistency}

\section{Recommendation}

Consistent terminology should be used to describe the various classes of DBEs.

\section{Conclusions}

10 CFR Part 60 currently contains many references to various events or conditions under which certain items must be designed to perform. Also, many sections of 10 CFR Part 60 are silent on the DBEs under which certain items should be designed to perform. Specific examples of the different terms or lack of terms used in 10 CFR Part 60 to describe the various classes of DBEs or conditions are presented in Table 1. The net effect is there may be uncertainty about application of the different classes 
Table 1. Examples of different terminologies used in 10 CFR Part 60 to describe design basis events or conditions.

\begin{tabular}{|c|c|}
\hline $\begin{array}{l}10 \text { CFR Part } 60 \\
\text { Citations }\end{array}$ & $\begin{array}{l}\text { Stated Design Basis Events or Design Conditions } \\
\text { Under Which Requirements Must be Met }\end{array}$ \\
\hline $21(\mathrm{c})(3)(\mathrm{i})$ & $\begin{array}{l}\text { Under normal conditions and under conditions that may result from } \\
\text { anticipated operational occurrences, including those of natural origin }\end{array}$ \\
\hline $21(\mathrm{c})(3)(\mathrm{ii})$ & Natural phenomena \\
\hline $\begin{array}{l}111(\mathrm{a}), 131(\mathrm{a}), 131(\mathrm{~b})(3)(\mathrm{iii}) \\
131(\mathrm{~b})(5)(\mathrm{ii}), 131(\mathrm{~b})(5)(\mathrm{iii}) \\
\text { 131(b)(9), 131(b)(10), 132(a), } \\
\text { 132(b), 132(c)(2), 132(d),132(e), } \\
\text { 133(a)(1), 133(b), 133(c), 133(d), } \\
\text { 133(e)(1), 133(e)(2), 133(f), } \\
\text { 133(g)(1), 133(g)(3), 137 }\end{array}$ & Not Stated \\
\hline $131(b)(1)$ & $\begin{array}{l}\text { Natural phenomena and environmental conditions anticipated at the } \\
\text { GROA }\end{array}$ \\
\hline $131(b)(2)$ & Equipment failure and similar events and conditions \\
\hline $131(\mathrm{~b})(3)(\mathrm{i})$ & During and after credible fires or 3xplosions in the GROA \\
\hline $131(\mathrm{~b})(3)(\mathrm{iv})$ & Operation or failure of fire suppression systems \\
\hline $131(\mathrm{~b})(4)(\mathrm{i})$ & During an emergency \\
\hline $131(\mathrm{~b})(4)(\mathrm{ii})$ & Emergency conditions \\
\hline $131(b)(5)(i)$ & Under both normal and accident conditions \\
\hline $131(b)(7)$ & $\begin{array}{l}\text { Under normal and accident conditions - unless at least two unlikely, } \\
\text { independent, concurrent or sequential changes have occurred in the } \\
\text { conditions essential to nuclear criticality safety }\end{array}$ \\
\hline $131(b)(8)$ & $\begin{array}{l}\text { Over anticipated ranges for normal operations and for accident } \\
\text { conditions }\end{array}$ \\
\hline $132(c)(1)$ & During normal operations \\
\hline $133(a)(2)$ & $\begin{array}{l}\text { Credible distuptive events during the period of operations, such as } \\
\text { floods, fires, and explosions }\end{array}$ \\
\hline $133(\mathrm{~g})(2)$ & During normal operations and under accident conditions \\
\hline
\end{tabular}

of DBEs to different types of structures, systems, and components. Standardized phraseology may he useful in 10 CFR Part 60 , and some changes may be useful to some of those regulatory citations listed in Table 1. 


\subsubsection{Radiation Protection}

\section{Recommendation}

It is clear that 10 CFR Part 60 is not limited to criteria for concentrations of radioactive materials in air of restricted areas [10 CFR 60.131(a)(1)], and that decontamination is not limited to decommissioning only [10 CFR 60.132(e)].

\section{Conclusion}

10 CFR 60.131(a) requires the GROA be designed to maintain radiation doses, levels, and concentrations of radioactive materials in air in restricted areas with in limits. Effluents in water or effluents to unrestricted areas are addressed by 10 CFR 60.111(a) referencing 10 CFR Part 20. Both 10 CFR Parts 60 and 72 require design to include means to monitor and control radioactive contamination. 10 CFR 72.126(a)(2) requires that the design must include means to decontaminate those systems to which access is required, 10 CFR 60.131(a)(4) requires the design to control dispersal of contamination for worker operational radiation safety, which would include design for decontamination during operations.

\subsubsection{Human-Induced Activity}

\section{Recommendation}

10 CFR 72.94(c).

Design considerations for "human-induced events" may be necessary to assure consistency with

\section{Conclusions}

10 CFR Part 60 is silent regarding the design of structures, systems, and components important to safety for human-induced events. Given the similarities between GROA surface facilities and a monitored retrievable storage installation (MRS), criteria regarding human-induced events may need to be addressed for completeness and consistency with 10 CFR Part 72.

\subsubsection{Emergency Response and Recovery}

\section{Recommendation}

Emergency response and recovery does not need to be clarified to make the design bases more general and consistent with 10 CFR $72.122(\mathrm{~g})$.

\section{Conclusions}

Since he occurrence of an emergency or a radiation accident would require several actions to be taken, it seems clear that response and recovery are part of the current requirements of $10 \mathrm{CFR}$ $60.131(\mathrm{~b})(4)$. It is clear that the terms "radiation accident" and "emergency" are closely related. 


\subsubsection{Concepts and Discussion}

\subsubsection{Design Criteria Consistency}

\section{Concept}

The terminology used for describing DBEs should be used in a standard well understood approach. Such terms could include: regular events, frequently occurring events, and infrequent events expected to occur during the lifetime of the GROA (Design Events I, II, and III), and credible events not expected to orcur during the lifetime of the GROA (Design Events IV) (NRC, 1989 and ANS, 1984).

\section{Discussion}

\section{CFR Part 60 Comparison}

The 10 CFR Part 60 citations, given in Table 1, use terms such as: "normal operations," "normal conditions," "anticipated operational occurrences," "accident conditions," etc. None of these is defined in 10 CFR Part 60. When these terms are compared to 10 CFR Parts 50 and 72, the use of similar undefined terms are found, however, "anticipated operational occurrences," is defined in the Definitions and Explanation section of Appendix A of 10 CFR Part 50.

\section{Concep: Comparison}

Standard terminology is not used in 10 CFR Part 60 and when compared to 10 CFR Parts 50 and 72 there are some differences in the terminologies used.

\subsubsection{Radiation Protection}

\section{Concept}

The GROA should be designed to maintain radiation doses, levels, and concentrations of radioactive material to meet the performance objectives. Additionally, the design should include a means to monitor and control the dispersal of radioactive contamination and to facilitate decontamination during operations.

\section{Discussion}

\section{CFR Part 60 Comparison}

10 CFR 60.131(a) limits its discussion to concentrations of radioactive materials in air in the restricted area and addresses effluents in water and effluents in unrestricted areas by 10 CFR 60.111(a) referencing 10 CFR Part 20. 10 CFR 72.126(d) requires control of radioactive material in all effluents. 10 CFR Part 50, Appendix A, Criterion 60 requires control of liquid and gas effluents to the environment.

10 CFR Part 60 currently requires decontamination in preparation for license termination (i.e., decommissioning) and addresses design for decontamination during the operational period in $10 \mathrm{CFR}$ 
60.131(a)(4). In the normal course of operations, contamination occurs and actions to limit its spread and ultimately its removal or decontamination are required. Design of certain systems should accommodate such a requirement. $10 \mathrm{CFR} 72.126(\mathrm{a})(2)$ requires design to include means to decontaminate those systems to which operational access is required.

\section{Concept Comparison}

The Concepi regarding exposure to radiation would require the GROA to be designed so that radiation exposures, levels, and concentrations of radioactive materials meet the limits of 10 CFR Part 20 and any applicable environmental standards established by the EPA during regular events, frequently occurring events, and infrequent events expected to occur during the lifetime of the GROA. This Concept is similar to the concepts in 10 CFR Parts 50 and 72.

The Concept regarding decontamination would require that design of the GROA facilitate decontamination. This would require design for decontamination capability during the period of GROA operations. This Concept is consistent with 10 CFR Part 72.

\subsubsection{Human-Induced Activity}

\section{Concept}

Structures, systems, and components important to safety should be designed so that natural phenomena, environmental conditions, and human-induced events (or human errors) will not interfere with their necessary safety functions.

\section{Discussion}

\section{CFR Part 60 Comparison}

10 CFR 60.131 (b)(1) currently includes protection against natural phenomena and environmental conditions, but does not explicitly include consideration of human-induced events. 10 CFR 72.94 requires consideration of external man-induced events that may endanger an independent spent fuel storage installation (ISFSI) or MRS.

\section{Concept Comparison}

The Concept regarding human-induced events calls for structures, systems, and components important to safety to be protected from natural phenomena, environmental conditions, as well as humaninduced events, which is consistent with 10 CFR Part 72.

\subsubsection{Emergency Response and Recovery}

\section{Concept}

Structures, systems, and components important to safety should be designed to (i) maintain control of radioactive waste and radioactive effluents; (ii) permit response, recovery, and prompt termination of operations; and (iii) provide for evacuation of personnel during a radiation accident or emergency. 


\section{Discussion}

\section{CFR Part 60 Comparison}

10 CFR 60.131(b)(4)(i) requires that structures, systems, and components important to safety be designed to maintain control of radioactive waste and effluents, and permit prompt termination of operacions and evacuation of personnel during an emergency. Other actions that may be required in the response to, and recovery from, emergencies are addressed in 10 CFR 60.131(b)(4)(ii). 10 CFR Part 72 requires structures, systems, and components important to safety to be designed for emergencies.

\section{Concept Comparison}

The Concept for emergency capability requires control of radioactive materials, termination of operations, and evacuation of personnel. The range of response capabilities necessary to protect the health and safety of personnel, includes the recovery from an emergency condition, (i.e., radiation accident). This would require that emergency response and recovery be included in designs and plans, which is consistent with the more generally phrased requirements of 10 CFR Part 72 .

\subsubsection{Elements Considered for Regulation}

\subsubsection{Design Criteria Consistency}

\section{Elements Considered}

Examples of terms that have similar meaning, but are used inconsistently throughout 10 CFR Parts 50, 60, 72, and 100 are:

- Anticipated operational occurrences

- Anticipated occurrences

- Expected operational occurrences

- Off-normal events

- Postulated events

- Credible disruptive events

- External events

- Design bases

- Design basis events

- Severe natural events

- Natural phenomena (event)

- Manmade phenomena and events

- Severe external man-induced events

- Transient conditions anticipated

- Design basis accident

- Postulated accidents

- Normal conditions

- Accident conditions

- Accidents

- Release of radiation 
- Major accident

- Serious accident

- Anticipated processes and events

- Unanticipated processes and events

- Emergencies

\section{Discussion on the Elements Considered}

Definition of terms and consistent use of terms is required regarding design for various DBEs and for radiation accidents or emergencies. This is in relation to those criteria which deal with GROA features that are necessary for radiological control that are not important to safety and those features that are important to safety. Correct and consistent use of these terms is essential to clearly state the relevant design criteria.

Features (facilities, equipment, processes, etc.) that are used for radiation control need to meet the radiation protection limits under Design Events I, II and III. The radiation protection limits in 10 CFR Part 20 and the EPA standards are the criteria to be used to determine if the design is adequate for Design Events I, II, and III. Features that are important to safety must also be designed to withstand Design Events I, II and III and to continue to perform their safety functions under Design Events IV (NRC, 1989 and ANS, 1984).

There may be events that are not considered in the design of the features of the GROA, even for those features that are important to safety. These events, which are beyond Design Events IV, have such a low probability of occurrence that it is essentially impossible for them to occur. Thus, it is unnecessary to require designing for these types of events. There still is the chance that such events could occur and result in a radiation accident (e.g., a release of radioactive material above the limits of 10 CFR Part 20). To provide defense-in-depth for such an eventuality, the site should be selected and plans made to protect the public from a postulated credible radiation accident.

\subsubsection{Radiation Protection}

\section{Elements Considered}

Elements for protection of the worker, and to some extent the public, require a wide variety of systems, equipment and procedures to (i) limit the spread of contamination and (ii) remove radioactive contamination, i.e., decontamination. These include:

- Alarm systems to warn of increased radiation levels or levels of radionu ides in the air

- Airborne and area monitoring systems

- Dose rate monitors

- Survey meters

- Hot cells and glove boxes

- Access control to contaminated areas during inspection, testing, maintenance, repair, and replacement

- Decontamination equipment, spills, kits, wipes, detection equipment, etc.

- Secondary waste handling facilities and equipment

- Personnel monitoring systems

- Shielding devices 
- Protective clothing and equipment

- Respirators

- Operational limitations or restrictions

- Operational exposures

- Time limits on exposure in high radiation areas

- Precautionary measures to be taken by workers in high risk areas

- Protection of waste/waste container from damage

- Ventilation and off-gas systems to confine airborne radioactive material

- Storage and confinement systems capable of continuous monitoring

- Equipment requirements would include:

- Air handling systems to clean and/or trap contaminated air

- Filters, ducts, and blowers

- Monitoring equipment for effluents (air and water)

- Information requirements

- Total volume of effluent, flow rates, and peak concentrations

- Expected human occupancy in the unrestricted area

- Water sampling capability

- Analyses of information to determine that releases meet the exposure limits

\section{Discussion on the Elements Considered}

10 CFR Part 60 requires the means to "monitor and control the dispersal of radioactive contamination" in 10 CFR 60.131(a)(4). This terminology could be interpreted to mean that control of contamination may be achieved by such means as: (i) painting over the contamination, (ii) changing the ventilation pattern, (iii) limiting access to the contaminated area, or (iv) decontaminating area surfaces. Generally speaking, contamination control is simply the act of confining contamination, while decontamination is the removal of contamination. Access control can be used to restrict traffic through an area that has been contaminated; and this can be an effective way to control the spread of contamination. However, use of the contaminated area is limited until the contamination is removed. One of the best solutions to a contamination problem is its removal. This prevents the further spread of contamination, elininates the need for access control, and restores the area for less-restricted access. Fixing the contamination in place is another operational solution, if the contamination levels are low or emit only low-penetrating radiation. Other criteria regarding decontamination, in 10 CFR 60.132(e), are within the context of decommissioning.

\subsubsection{Human-Induced Activity}

\section{Elements Considered}

Elements of human-induced activities that may need to be considered as DBEs are:

- Operator errors

- Installation errors

- Accident caused by workers (e.g., fires, releases of toxic materials)

- Sabotage

- Offsite releases of toxic materials

- Offsite explosions

- Airplane crashes 


\section{Discussion on the Elements Considered}

10 CFR 60.131(b)(1) currently includes protection against natural phenomena and environmental conditions, but is silent regarding human-induced events. Conversely, 10 CFR 72.94 requires consideration of potential man-induced events that may endanger an ISFSI or MRS.

\subsubsection{Emergency Response and Recovery}

\section{Elements Considered}

Elemerits of emergency response and recovery would include the following:

- Surface areas can be decontaminated, i.e., floors, walls, and ducts

- Monitoring equipment, e.g., air samplers, survey instruments, portable monitors, area dosimetry

- Control gates, fences, and checkpoints

- Emergency alarm and notification systems included in design

- Area surveillance equipment, e.g., cameras, etc.

- Heating, ventilation and air conditioning design, filters, flow diverters, dampers, etc.

- Shielding emplaced for potential emergencies

- Building containment for potential emergencies

- Evacuation routes incorporated in design

- Communications systems designed for radiological emergencies

- Utilities designed for radiological emergencies

\section{Discussion on the Elements Considered}

Design criteria need to address the conditions under which the design must function. In describing the design requirements for facilities and equipment that are important to safety, it is necessary to consider conditions other than normal events, i.e., Design Events IV (ANS, 1984). An emergency may arise because it is not required, nor expected, that the design should consider those events having a very low probability of occurrence.

\subsubsection{Safety Functions and Regulatory Citations}

\subsubsection{Safety Functions}

\section{Design Criteria Consistency}

There are no safety functions (Romine, 1992) associated with the consistent use of terminology.

\section{Radiation Protection}

The safety functions (Romine, 1992) are:

Decontaminate waste disposal package surface areas during/following waste packaging (as required) - 5.8.11 
Decontaminate transportation package/waste surface areas in receiving (if required) - 6.2.3

Monitor repository conditions that affect radiological health and safety or isolation during repository operations -6.8

Continuously monitor conditions that may impact personnel safety (radiological \& non-radiological) during repository operations - 6.8.1

Continuously monitor radiation levels during repository operations - 6.8.1.1

Monitor environmental conditions to provide warning of potentially hazardous conditions or events during repository operations (e.g., air contamination, seismic event) - 6.8.1.2

Continuously monitor personnel radiation exposure levels during repository operations -6.8 .1 .3$

Continuously monitor conditions that may impact radiological exposures, releases and/or containment during repository operations -6.8 .2$

Decontaminate waste disposal package surface area(s) during waste removal operations (if required) - 6.9.11

Decontaminate underground facilities and equipment (if required) - 6.11.1.1

Decontaminate and dismantle surface facilities -6.11 .3$

Decontaminate surface facilities (as necessary) - 6.11.3.1

Consolidate and transfer contaminated equipment and materials - 6.11.3.4

Dispose of contaminated equipment and materials during closure operations (as authorized) - 6.11.3.5

Limit spread of contamination during waste disposal operations - 6.16.2.2

Decontaminate in event of release during waste disposal operations - 6.16.2.3

Limit radiation level during waste disposal unsafe/emergency conditions - 6.16.2.4

Decontaminate in event of accidental release (if possible) - 6.17.3.3

Equipment for monitoring and alarm during repository operations - 6.41.6.2

Contaminated material processing and package facility (if required) - 6.41.9.1.6

Closure and decommissioning equipment and materials - 6.41.9.2

Contaminated material processing and packaging equipment (if required) - 6.41.9.2.8 
Procedure(s) for decontamination - 6.41.9.5.6

\section{Human-Induced Activity}

The safety function (Romine, 1992) is:

Ensure the ability of repository facilities and equipment important to safety or isolation to perform their intended functions under conditions and events induced by human activity - 6.36

\section{Emergency Response and Recovery}

The safety functions (Romine, 1992) are:

Limit spread of contamination during waste preparation operations - 5.16.2.2 [sic], (5.16.7.2)

Re-establish control of radioactive material at the source in event of accidental release during waste preparation operations - 5.17.3.1

Limit spread of contamination in event of accidental release during waste preparation operations (if possible) - 5.17.3.2

Decontaminate in event of accidental release during waste preparation operations (if possible) - 5.17.3.3

Implement worker/public evacuation plan as appropriate in event of accidental release during waste preparation operations - 5.17.3.4

Monitor environmental conditions to provide warning of potentially hazardous conditions or events during repository operations (e.g., air contamination, seismic event) - 6.8.1.2

Continuously monitor conditions that may impact radiological exposures, releases and/or containment during repository operations -6.8 .2$

Limit consequences of accidental radionuclide releases during waste disposal operations - 6.17.3 Reestablish control of radioactive material at the source in event of accidental release -6.17 .3 .1$

Limit spread of contamination in event of accidental release (if possible) - 6.17.3.2

Decontaminate in event of accidental release (if possible) - 6.17.3.3

Implement worker/public evacuation plan as appropriate in event of accidental release - 6.17.3.4

\subsubsection{Relevant Regulatory Citations}

- 10 CFR Part 50, Appendix A, Definitions and Explanations and Criterion 60

- 10 CFR 60.21(c)(3), 60.111(a), 60.131(a), 60.131(b)(1), 60.131(b)(2), 60.131(b)(3)(i), 60.131(b)(3)(iii), 60.133(b)(3)(iv), 60.131(b)(4), 60.131(b)(4)(i), 60.131(b)(4)(ii), 
60.131(b)(5)(i), 60.131(b)(5)(ii), 60.131(b)(5)(iii), 60.131(b)(7), 60.131(b)(8), 60.131(b)(9), 60.131(b)(10), 60.132(a), 60.132(b), 60.132(c)(1), 60.132(c)(2), 60.132(d), 60.132(e), 60.133(a)(1), 60.133(a)(2), 60.133(b), 60.133(c), 60.133(d), 60.133(e)(1), 133(e)(2), $60.133(\mathrm{f}), 60.133(\mathrm{~g})(1), 60.133(\mathrm{~g})(2)$

- 10 CFR $72.94,72.122(\mathrm{~g}), ' 12.126(\mathrm{a})(2), 72.126(\mathrm{~d})$

\subsection{SITING CRITERIA}

This ROC Topic has the following subtopics:

(1) Establish a Preclosure Controlled Area and Individual Dose

(2) Accident Analysis

(3) Collective Dose

(4) Preclosure Site Assessment

(5) Preclosure Regional Impact

\subsubsection{Recommendations and Conclusions}

\subsubsection{Establish a Preclosure Controlled Area and Individual Dose}

\section{Recommendation}

Criteria are needed which would require the establishment of a controlled area or controlled-use area, for the preclosure period of the GROA. The criteria should be consistent with existing rules to the extent practicable. The criteria should provide dose values (e.g., total effective dose equivalent of 5 rems $(0.05 \mathrm{~Sv})$, an eye dose of 15 rems $(0.15 \mathrm{~Sv})$, and $50 \mathrm{rems}(0.50 \mathrm{~Sv})$ committed dose equivalent to any individual organ other than the lens of the eye) for evaluating the adequacy of the boundary of the controlled area or controlled-use area.

\section{Conclusions}

Failure of a structure, system, or component may result in some radiation protection limits being exceeded. The siting of a nuclear facility, such as a geologic repository, needs to consider the potential effects of an accidental release of radioactive material or accidental direct exposure to radiation. There is a need to address a controlled area or controlled-use area to protect the public from radiation accidents that may result from an event at the HLW geologic repository before permanent closure. This should be accomplished by requiring the establishment of a controlled area or controlled-use area and providing exposure criteria for evaluating the adequacy of the area's boundary.

\subsubsection{Accident Analysis}

\section{Recommendation}

A new requirement should be added to 10 CFR Part 60 , requiring an analysis of the potential total effective dose equivalent and/or organ doses to a hypothetical individual located on or beyond the boundary of the controlled area or controlled-use area, similar to the provision of 10 CFR 72.106. 


\section{Conclusions}

The proposed changes to 10 CFR Part 60, to establish a controlled area or controlled-use area, may also make it necessary that a dose analysis be prepared by the licensee in support of a license application. 10 CFR $72.24(\mathrm{~m})$ may serve as a model for a dose analysis requirement.

\subsubsection{Collective Dose}

\section{Recommendation}

Since 10 CFR Part 20 has no criteria for collective doses and 10 CFR Part 72 does not address either collective doses or a population center distance (PCD), neither of these concepts should be included in 10 CFR Part 60. This will maintain consistency with 10 CFR Part 72 and it avoids conflict with 10 CFR Part 20.

\section{Conclusions}

Since 10 CFR Part 20 only defined the term "collective dose" and does not include any criteria for a collective dose or population dose, it is considered premature to address collective doses for a radiation accident in 10 CFR Part 60 . A definition for PCD is closely associated with a collective dose and it is considered premature to include such a concept in 10 CFR Part 60.

\subsubsection{Preclosure Site Assessment}

No recommendation is offered because the criteria in 10 CFR $60.21(\mathrm{c})(1)$ are general in nature, and therefore, can address any needed site assessments for preclosure designs and the matter need not be pursued further.

\subsubsection{Preclosure Regional Impact}

No recommendation is offered because the impact of GROA activities will be addressed in the Department of Energy (DOE) Environmental Impact Statement (EIS), per 10 CFR 60.21(a) and 60.51(a). Therefore, no further action is necessary.

\subsubsection{Concepts and Discussion}

\subsubsection{Establish a Preclosure Controlled Area and Individual Dose}

\section{Concept}

One of the tenets of NRC defense-in-depth philosophy is that a facility should be sited, designed, and operated with additional features to protect the public from consequences or events that are not expected but yet are considered credible. Siting criteria should address a controlled area or controlled-use area for a maximum hypothetical individual exposure, should a radiation accident occur as the result of a DBE. The dose criterion for evaluating the adequacy of the controlled area or controlled-use area boundary, for postulated credible preclosure radiation accidents, should not be greater than the annual occupational limits for a worker. This criterion would apply to any individual located 
at any physical boundary of the controlled area or controlled-use area. The controlled area or controlleduse may be traversed by a highway, railroad, or waterway, so long as appropriate and effective arrangements are made to control traffic and to protect public health and safety.

\section{Discussion}

\section{CFR Part 60 Comparison}

10 CFR Part 60 is silent regarding a radiation accident that may result from a DBE. Siting can be used to further protect the public health and safety if a radiation accident occurs. Also, many actions can be taken to (i) help control the radiation exposure to workers and the public, (ii) continue to safeguard the HLW, and (iii) recover from the results of the radiation accident. The response actions taken will depend on the extent to which the radiation protection limits have been exceeded (i.e., the severity of the radiation accident). In contrast, 10 CFR Parts 50 and 72 both have criteria for a radiation accident or design basis accident.

10 CFR Part 60 contains postclosure siting criteria, but is silent regarding preclosure siting criteria to protect the health and safety of the public should a DBE cause a radiation accident. By contrast, both 10 CFR Parts 50 and 72 contain siting criteria for the protection of public health and safety, where 10 CFR 72.106 provides a dose criterion of 5 rems $(0.05 \mathrm{~Sv})$ for whole body or any organ. 10 CFR Part 50 has siting criteria by its reference to 10 CFR 100.11. 10 CFR Part 60 does not currently contain any individual radiation exposure values that could be used as siting criteria to protect the public in the event of a radiation accident. 10 CFR Parts 72 and 100 both contain individual radiation exposure criteria for use in siting.

\section{Concept Comparison}

The Concept above would require the consideration of postulated credible radiation accidents that could occur for a given facility design in the siting of a geologic repository. The facility and its surrounding features should be planned such that the impact and the risks of a radiation accident are both controllable and minimized. In order for a geologic repository to provide the necessary radiation protection from a radiation accident, siting criteria are needed. This concept is consistent with the approach taken in 10 CFR Part 72 and 10 CFR Part 100.

\subsubsection{Accident Analysis}

\section{Concept}

In the process of siting a geologic repository, analysis is needed of the potential total effective dose equivalent or an organ dose to an individual located on or beyond the boundary of the controlled area or controlled-use area based on a radiation accident caused by any credible DBE. The calculations of potential total effective dose equivalent to an individual or organ dose must be performed for the primary dose contributors, which may include direct radiation exposure, inhalation, and ingestion occurring as a result of such a radiation accident. 


\section{Discussion}

\section{CFR Part 60 Comparison}

As discussed above, 10 CFR Part 60 is silent regarding the establishment of a controlled area or controlled-use area that is similar to that defined in 10 CFR Parts 20 and 72 . As a result, there is no requirement to provide an analysis of the potential dose to an individual at or beyond the boundary of the controlled area or controlled-use area.

\section{Concept Comparison}

The Concept contains language similar to the text contained in 10 CFR 72.24(m), therefore there is no significant difference between the Concept and 10 CFR Part 72.

\subsubsection{Collective Dose}

\section{Concept}

Any preclosure siting criteria proposed for 10 CFR Part 60 should not address a collective dose (total dose to a specified population), as is implied by 10 CFR 100.11(a)(3). The supplementary information of a rulemaking may need to point out that not having a collective dose assessment for radiation accidents, at this time, is consistent with 10 CFR Part 72 and the new 10 CFR Part 20.

\section{Discussion}

\section{CFR Part 60 Comparison}

Neither 10 CFR Parts 60 nor 72 has criteria for a collective dose or PCD. 10 CFR Part 20 defines the term "collective dose" but does not have any criteria for a collective dose.

\section{Concept Comparison}

The above Concept does not call for a definition of PCD or collective dose, which maintains consistency with 10 CFR Parts 20 and 72.

\subsubsection{Preclosure Site Assessment}

\section{Concept}

General site assessment criteria for preclosure issues should be in 10 CFR Part 60.

\section{Discussion}

Siting criteria contained in 10 CFR 60.122 are related to postclosure concerns only (NRC, 1990). Site assessment for the preclosure phase is not addressed in 10 CFR Part 60 at the same level of detail as 10 CFR Part 72. However, the current 10 CFR 60.21(c)(1) will, in general terms, address the same concepts presented in 10 CFR Part 72. Since 10 CFR 60.21(c)(1) requires a description of the site 
assessment, especially for those features which might affect the design and performance of the GROA, the concept has been addressed by 10 CFR Part 60 .

\subsubsection{Preclosure Regional Impact}

\section{Concept}

Part 60.

The regional impact of the preclosure activities of the GROA should be addressed in 10 CFR

\section{Discussion}

10 CFR Part 60 fully addresses the assessment of the preclnsure regional impact of the GROA on the public and the environment, but in a different manner from that in 10 CFR 72.34, 72.98, 72.100, and 72.108. The impact of GROA activities will be fully addressed in the DOE EIS, per 10 CFR $60.21(\mathrm{a})$ and $60.51(\mathrm{a})$.

\subsubsection{Elements Considered for Regulation}

\subsubsection{Establish a Preclosure Controlled Area and Individual Dose}

\section{Elements Considered}

The site should allow establishing an area to control access, such as, a controlled area or controlled-use area. For the control of access based on any credible DBE which results in a radiation accident the controlled area or controlled-use area would consider such factors as: land ownership, residents, traffic patterns, site characteristics, maximum source term or inventory, and meteorological conditions. The site could also allow for a minimum distance from the waste handling and storage facilities (e.g., 100 meters). A controlled area or controlled-use area is a boundaried area (fenced or marked and patrolled) to control access should an accidental radioactive material release or radiation exposure occur (e.g., fences, guard gates, surveillance systems, warning devices for personnel and public, lighting for night access control).

A term that conveys the use of a 10 CFR Part 72-type controlled area that applies until permanent closure (the preclosure phase) is controlled area or sontrolled-use area. Since the term "controlled area" is already defined in 10 CFR Part 60, a new term, such as controlled-use area, which is similar to an MRS controlled area or a nuclear plant exclusion area, may need to be introduced. However, if the term "controlled area" is to be consistent with 10 CFR Part 20, then the term "postclosure-controlled area" could be used to describe the current controlled area.

10 CFR Part 60 may need to ensure that a potential site will allow establishing a controlled area or controlled-use area in such a way to ensure an individual dose value for a postulated credible radiation accident will not be exceeded, considering land ownership, existing residents, traffic patterns, site characteristics, source term, meteorological conditions, etc. A controlled area or controlled-use area, concerned with the preclosure period, should be identified during site characterization so that it is assured that the site can support such an area during the operational phase from receipt of waste, until permanent closure. If a controlled area or controlled-use area is defined to address the maximum exposure to any 
individuai outside the boundary for the entire duration of a postulated radiation accident then a low population zine, as given in 10 CFR 100.11 , is not necessary. Also, using the boundary of the restricted area (as defined in 10 CFR Part 20) as the physical area required for limiting exposures to the public from postulated credible radiation accidents may be inconsistent with the intent of the restricted area to control access to trained and monitored radiation workers.

\section{Discussion on Elements Considered}

One element of the defense-in-depth philosophy is to provide for the establishment of a controlled area or controlled-use area from which members of the public can be excluded if a postulated radiation accident should result from a credible DBE. In order to determine the size of such an area, it is necessary that a dose value for a hypothetical individual located at any point on the boundary be established. The dose value selected should be appropriate to assure that the occurrence of a postulated radiation accident does not present any unreasonable risk to the health and safety of the public. The values suggested for a postulated radiation accident resulting from a credible DBE are the 10 CFR Part 20 annual occupational limits for an adult. Considering the low probability of occurrence and limited potential injury, the resulting risk to the public health based upon annual occupational limits would not be unreasonable.

The existing terminology in 10 CFR Part 60 differs from the language of 10 CFR Part 20 especially regarding the terms "controlled area" and "site" (or "site boundary"). Some changes in terminology may be desirable in a potential rulemaking to reduce these apparent inconsistencies. If 10 CFR Part 60 is to be consistent with 10 CFR Part 72, then it may be necessary for consideration of an ingestion pathway as well as direct exposure and inhalation. However, since removal of members of the public is inherent in the controlled area or controlled-use area concept, the ingestion pathway may have little significance.

An uncertainty about accident dose limits was identified by Weiner, et. al., 1990 on page B-40. The NRC staff recommended a major rulemaking dealing with a radiation dose criteria for accidents for Uncertainty Reference Number 15, page 19 of Appendix A of NRC, 1991.

The exposure value for the controlled area in 10 CFR $72.106(\mathrm{~b})$ is 5 rems $(0.05 \mathrm{~Sv})$ to the whole body or any organ. This value is the same as the upper value for a whole body dose for protective action guidance (EPA, 1991). On page 2-6 of EPA, 1991 a range of 1-5 rems (0.01-0.05 Sv) whole body dose is given as a protective action guide for those cases where there are no major local constraints in providing protection.

\subsubsection{Accident Analysis}

\section{Elements Considered}

Elements to be considered in regards to accident analysis and of inventory control (to assure that the maximum limits for radioactive material are not exceeded) are:

- Determine the potential dose equivalent to an individual outside the controlled or controlleduse area that is attributable to DBEs

- Determine DBEs and demonstrate by conservative analysis that the doses outside the controlled-use area would meet applicable standards 
- Inventory hardware and software

- Records management system

- Controls to limit the source term to the maximum used for calculating the maximum possible release and exposure to radiation

\section{Discussion of Elements Considered}

The criterion for accident analysis might be best related to 10 CFR 60.21 .

\subsubsection{Collective Dose}

\section{Elements Considered}

The site should not be too close to a densely populated area so that the total integrated population dose is acceptable should a postulated radiation accident occur.

\section{Discussion of the Elements Considered}

A PCD is defined in 10 CFR 100.3 as, "the distance from the reactor to the nearest boundary of a densely populated center containing more than about 25,00 residents." In 10 CFR 100.11, a PCD is identified such that it is at least one and one-third times the distance from the facility to the outer boundary of the low population zone. In applying this guide, the boundary of the population center shall be determined upon consideration of population distribution. Political boundaries are not controlling in the application of this guide. Where very large cities are involved, a greater distance may be necessary because of total integrated population dose consideration.

The elements considered show that locating a repository (where a large quantity of radioactive material would be received and handled for a long period of time) in or near a large population center may need to be controlled so as to minimize the potential total integrated population dose should a postulated radiation accident occur during the operational period.

The NRC is concerned with siting criteria for both the preclosure and postclosure phases of a repository. The NRC states, "The Commission is persuaded that population factors may need to be considered in connection with the period when wastes are being received and emplaced through evaluation of the adequacy of DOEs emergency plan" (NRC, 1991). It has been shown that emergency plans may not be effective if the affected local communities are unresponsive to the emergency plan. A lack of response could be caused by population/siting factors or by lack of local government cooperation. In order to best protect the public, it may be necessary to control the integrated population dose by more than emergency planning alone. However, 10 CFR Part 20 does not recommend collective dose criteria for normally expected operations, therefore collective dose criteria for rare events would be tenuous at this time.

\subsubsection{Preclosure Site Assessment}

\section{Elements Considered}

The elements considered in this subtopic are: 
- Regulatory organization

- Postclosure siting criteria

- Preclosure siting criteria

- Surface and underground facility siting criteria

- Human-induced hazard considerations

- Population density and proximity

- Aircraft and missile hazards

- Induced seismicity

- Industrial accidents

- Natural-hazard considerations

- Seismic magnitude and frequency

- Soil and rock properties

- Volcanism

- Fault displacement

- Groundwater

- Surface water

\section{Discussion on Elements Considered}

There are three elements of 10 CFR Part 60 that may be enhanced by further guidance. They include: (i) specific preclosure site investigation criteria, (ii) separate preclosure surface and underground siting criteria, and (iii) kinds and extent of investigations required for acquisition of data to satisfy the preclosure siting criteria. 10 CFR Part 60 provides few details regarding investigations required other than in 10 CFR $60.21(c)(1)$.

\subsubsection{Preclosure Regional Impact}

\section{Elements Considered}

The elements considered in this subtopic are:

- Identification of those radiological health concerns associated with the receipt and off-site shipping of waste

- Population density along available routes

- Local police, fire and emergency response facilities

- Identification and investigation of those vulnerable characteristics of the proposed site, including routes to be used for shipping

- Route conditions

- Route alternatives

- Expected rate of movement versus locale

- Environmental influences, i.e., weather impact on accidents and releases

\section{Discussion on Elements Considered}

10 CFR Part 60 currently contains no preclosure siting criteria for preclosure operations, as does 10 CFR Part 72, however, the EIS required for the geologic repository would adequately address the assessment of the GROA preclosure impact on the surround region. 


\subsubsection{Safety Functions and Regulatory Citations}

\subsubsection{Safety Functions}

\section{Establish a Preclosure Controlled Area and Individual Dose}

The safety functions (Romine, 1992) are:

Minimize likelihood of accidental releases of radionuclides during waste disposal operations - 6.17 .2

Limit consequences of accidental radionuclide releases during waste disposal operations - 6.17.3

Reestablish control of radioactive material at the source in event of accidental release - 6.17.3.1

Limit spread of contamination in event of accidental release (if possible) - 6.17.3.2

Decontaminate in event of accidental release (if possible) - 6.17.3.3

Implement worker/public evacuation plan as appropriate in event of accidental release - 6.17.3.4

Limit radiation level in the unrestricted area due to waste preparation operations 6.18

Establish a controlled area - 7.4.1

\section{Accident Analysis}

There are no safety functions (Romine, 1992) associated with accident analysis.

\section{Collective Dose}

There are no safety functions (Romine, 1992) associated with exposure values for a collective dose.

\section{Preclosure Site Assessment}

There are no safety functions (Romine, 1992) associated with preclosure site assessment.

\section{Preclosure Regional Impact}

There are no safety functions (Romine, 1992) associated with preclosure regional impact.

\subsubsection{Relevant Regulatory Citations}

- 10 CFR 60.21(a), 60.21(c)(1), 60.51(a), and 60.122

- 10 CFR 72.24(m), 72.34, 72.98, 72.100, 72.106, and 72.108

- 10 CFR 100.3 and 100.11 


\subsection{DEFINITIONS}

This ROC Topic has the following subtopics:

(1) Design Bases and Design Basis Events

(2) Important to Safety

(3) Controlled Area or Controlled-use Area

(4) Postclosure-controlled Area

(5) Site and Site Boundary

\subsubsection{Recommendations and Conclusions}

\subsubsection{Design Bases and Design Basis Events}

\section{Recommendation}

Definition of the terms "design bases" and "DBEs" should be provided. This could be accomplished by an explanation in the supplementary information of a rulemaking, or by adding new definitions to 10 CFR Part 60 such as the definition of the term "design bases" in 10 CFR Part 72 .

\section{Conclusions}

10 CFR Part 60 is silent regarding what design bases and DBEs mean within the context of the regulation. Explaining the meaning or adding definitions would (i) ensure clarity of the regulatory intent, (ii) be consistent with other text already in the regulation, and (iii) be consistent with 10 CFR Part 72 .

\subsubsection{Important to Safety}

\section{Recommendation}

The definition of the expression "important to safety" in 10 CFR Part 60 should be changed to be more consistent with the definition of the phrase "structures, systems, and components important to safety" in 10 CFR Part 72.

\section{Conclusions}

10 CFR Parts 50, 60, and 72 all concern facilities involved with HLW or highly radioactive materials. Each of these regulations uses and defines terms containing the phrase "important to safety." To assure defense-in-depth, structures, systems, and components important to safety have additional design and quality assurance requirements, as compared to other structures, systems, and components that are not important to safety. The 10 CFR Part 60 definition of important to safety may cause uncertainties because it (i) may fail to address radiation worker protection within its concepts, and (ii) may be interpreted to include all structures, systems, and components, not just those associated with HLW.

The Concept of important to safety associates equipment with HLW, as does the 10 CFR Part 72 definition of structures, systems, and components important to safety. HLW represents a much more 
significant hazard than does low-level waste. Therefore, items that are important to safety should have additional design requirements than the items associated with low-level waste.

\subsubsection{Controlled Area or Controlled-use Area}

\section{Recommendation} CFR 60.2.

A new definition of the term "controlled area" or "controlled-use area" should be added to 10

NOTE: The current definition of the term "controlled area" in 10 CFR Part 60 may need to be renamed as the "postclosure-controlled area" to ensure consistency with the new 10 CFR Part 20 [see the discussion in (4) Postclosure-controlled Area, below]. Other requirements in 10 CFR Part 60, which currently reference a controlled area, would require an editorial substitution of the phrase "postclosurecontrolled area" for "controlled area." Sections within 10 CFR Part 60 where these changes may be required are listed below:

$\begin{array}{lll}60.2 & 60.43(\mathrm{~b})(5) & 60.122(\mathrm{~b})(6) \\ 60.21(\mathrm{c})(1)(\mathrm{i}) & 60.46(\mathrm{a})(3) & 60.122(\mathrm{c}) \\ 60.21(\mathrm{c})(1)(\mathrm{ii})(\mathrm{B}) & 60.51(\mathrm{a})(2) & 60.122(\mathrm{c})(12) \\ 60.21(\mathrm{c})(3) & 60.102(\mathrm{c}) & 60.122(\mathrm{c})(17) \\ 60.21(\mathrm{c})(7) & 60.121(\mathrm{a})(1) & 60.122(\mathrm{c})(18) \\ 60.21(\mathrm{c})(8) & 60.121(\mathrm{~b}) & 60.122(\mathrm{c})(19)\end{array}$

\section{Conclusions}

For preclosure safety there is no controlled area or controlled-use area in 10 CFR Part 60 . The new 10 CFR Part 20 may force a change of the term controlled area in 10 CFR Part 60 due to a conflict in the use of terminology. 10 CFR 20.1002 states that Part 20 applies to licenses issued pursuant to 10 CFR Part 60 . In addition, 10 CFR Part 60 requires adherence to 10 CFR Part 20. 10 CFR Part 20 defines the term "controlled area" in a manner similar to 10 CFR Part 72. This definition is also similar to the definition of the term "exclusion area" in 10 CFR 100.3. 10 CFR Part 20 also uses the term "controlled area" in its definition of the term "public dose."

\subsubsection{Postclosure-controlled Area}

\section{Recommendation}

The concept contained in the current definition of "controlled area" found in 10 CFR Part 60 is valid and should be retained. However, it may be necessary to provide a different title or term for the definition, such as "postclosure-controlled area" to avoid confusion, and eliminate inconsistencies with the definitions in 10 CFR Parts 20 and 72.

\section{Conclusions}

Providing a new title would necessitate editorial changes to 10 CFR 60.43(b)(5), 60.46(a)(3), $60.51(\mathrm{a})(2)$, and $60.102(\mathrm{c})$ to incorporate the new term, "postclosure-controlled area." Additional 
changes in 10 CFR 60.2 to some definitions which use the term "controlled area" within the context of the current definition would also be required.

\subsubsection{Site and Site Boundary}

\section{Recommendation}

The definition of the term "site" in 10 CFR Part 60 may need to be made compatible with the definition of "site boundary," in 10 CFR 20.1003.

\section{Conclusions}

In general, the term "site" is used in 10 CFR Part 60 in an easily understood context, especially when associated with site characterization. Where the term "site" is specifically intended to mean the postclosure-controlled area, 10 CFR Part 60 may need to be changed to reflect this intent. Editorial changes may be needed for the following citations of 10 CFR Part 60 to reflect the 10 CFR Part 20 definition of "site boundary."
$60.21(\mathrm{c})(8)$
$60.122(\mathrm{c})(12)$
$60.102(c)$
$60.122(c)(17)$
$60.122(\mathrm{c})(18)$
$60.122(c)(19)$

The previous discussion about a controlled area has shown that the 10 CFR Part 60 definition of the term "controlled area" may be in conflict with other regulations. Therefore, the definition of a "site" in 10 CFR Part 60 may also be in conflict with other regulations because it defines the term "site" as the location of controlled area.

\subsubsection{Concepts and Discussion}

\subsubsection{Design Bases and Design Basis Events}

\section{Concept}

Design bases mean that information that identifies the specific functions to be performed by a structure, system, or component of a facility and the specific values or ranges of values chosen for controlling parameters as reference bounds for design. These values may be restraints derived from generally accepted state-of-the-art practices for achieving functional goals or requirements derived from analysis (based on calculation or experiments) of the effects of a credible event, under which a structure, system, or component must meet its functional goals. The values for controlling parameters for external events include: (i) estimates of severe natural events to be used for deriving design bases that will be based on consideration of historical data on the associated parameters, physical data, or analysis of upper limits of the physical processes involved and (ii) estimates of severe external human-induced events to be used for deriving design bases that will be based on analysis of human activity in the region taking into account the site characteristics and the risks associated with the events.

Design basis events mean (i) those events that can reasonably be expected to occur prior to permanent closure and (ii) such other natural and human-induced events that are considered unlikely, but 
are sufficiently credible to warrant consideration, which are postulated because their consequences may result in maximum potential impacts on the environs of the GROA.

Discussion

\section{CFR Part 60 Comparison}

10 CFR Parts 50 and 72 both define the term "design bases" and 10 CFR Part 50 defines DBEs. 10 CFR Part 60 is silent regarding a definition of "design bases," even though it uses the expression several times, i.e., 10 CFR 60.21(c)(2)(ii), 60.73(b), 60.130, and 60.141(d). Also, 10 CFR Part 60 does not define or utilize the term DBE.

\section{Concept Comparison}

The Concept provides definitions of the terms "design bases" and "DBEs," which are essentially the same as the definitions for design bases, in 10 CFR Part 72, and DBEs, in 10 CFR 50.49(b)(1).

\subsubsection{Important to Safety}

\section{Concept}

The term "important to safety" means important: (i) to maintain the conditions required to store HLW safely, (ii) to prevent or mitigate damage to HLW or HLW containers during handling or storage, or (iii) to provide reasonable assurance that HL.W can be received, handled, packaged, stored, and retrieved without undue risk to the health and safety of the public.

\section{Discussion}

\section{CFR Part 60 Comparison}

10 CFR Parts 50, 60, and 72 respectively contain definitions for "safety-related electrical equipment," "important to safety," and "structures, systems, and components important to safety." With the exception of 10 CFR Part 60, these definitions have the same concept, i.e., identifying items (having additional design and quality assurance requirements) required for protecting radiation workers and the public. The definition in 10 CFR Part 60 provides for protection of the public, but protection of workers may be excluded. The primary differences are: (i) different definitions of similar terms and (ii) different concepts.

\section{Concept Comparison}

The Concept calls for a definition of the term "important to safety" which is similar to the definition of structures, systems, and components important to safety in 10 CFR Part 72 . The Concept definition for important to safety also calls for the second part of the definition to include a reference to damage to waste packages. As receiving, packaging, and retrieval are specific elements of operations, other specific operational elements are also vital to defense-in-depth necessary for HLW. These other operational elements include: receipt, transport (onsite-transportation), packaging, containment, shielding, emplacement, disposal (storage and handling), and retrieval. 


\subsubsection{Controlled Area or Controlled-use Area}

\section{Concept}

A controlled area or controlled-use area means an area outside of a restricted area but inside the site boundary, access to which can be limited by the licensee for any reason.

\section{Discussion}

\section{CFR Part 60 Comparison}

10 CFR Part 60 currently contains a definition of a "controlled area," however, this definition applies only to the postclosure time frame and, therefore, is not applicable to preclosure operations. This definition is now in conflict with the definition of "controlled area" contained in the new 10 CFR Part 20. The 10 CFR Part 20 definition is conceptually consistent with the definition of "controlled area" in 10 CFR Part 72 and "exclusion area" in 10 CFR 100.3. Since the GROA must be designed so that radiation exposures and radiation levels are maintained within the limits of 10 CFR Part 20 which defines the term "public dose" using the term "controlled area," this terminology in 10 CFR Part 60 may need to be consistent with that in 10 CFR Part 20. This could be accomplished by renaming the current 10 CFR 60.2 definition of "controlled area" as the "postclosure-controlled area," by introducing a new definition of "controlled area," which is the same as 10 CFR Part 20; or by using the term "controlleduse area" similar to 10 CFR Part 72's term for a "controlled area." This difference can be characterized as: (i) a difference in the definition of terms and (ii) a difference in concepts.

\section{Concept Comparison}

The Concept for the definition of "controlled area" or "controlled-use area" is the same as the definition of "controlled area" contained in both 10 CFR Parts 20 and 72.

\subsubsection{Postclosure-controlled Area}

\section{Concept}

The term "postclosure-controlled area" means a surface location, to be marked by suitable monuments, extending horizontally no more than 10 kilometers in any direction from the outer boundary of the underground facility, and the underlying subsurface, which area has been committed to use as a geologic repository and from which incompatible activities would be restricted following permanent closure.

\section{Discussion}

The above change in terminology or title would only require changes to the following definitions in 10 CFR 60.2, as indicated:

"Accessible environment" means: (i) the atmosphere, (ii) the land surface, (iii) surface water, (iv) oceans, and (v) the portion of the lithosphere that is outside the postclosure-controlled area. 
"Disturbed zone" means that portion of the postclosure-controlled area the physical or chemical properties of which have changed as a result of underground facility construction or as a result of heat generated by the emplaced radioactive wastes such that the resultant change of properties may have a significant effect on the performance of the geologic repository.

\section{CFR Part 60 Comparison}

10 CFR Part 60 currently contains a definition of the term "controlled area," however, this definition applies only to the postclosure time frame and, therefore, is not applicable to preclosure operations. This definition may now be in conflict with the definition of "controlled area" contained in the new 10 CFR Part 20. The 10 CFR Part 20 definition is conceptually consistent with the definition of "controlled area" in 10 CFR Part 72 and "exclusion area" in 10 CFR 100.3. Since the GROA must be designed so that radiation exposures and radiation levels are maintained within the limits of 10 CFR Part 20 which defines "public dose" using the term "controlled area," this terminology in 10 CFR Part 60 should be consistent with that in 10 CFR Part 20.

\section{Concept Comparison}

The purpose of this definition is to describe an area where human activity is to be restricted during the postclosure period. If the NRC proposes to use another definition for "controlled area," which is consistent with 10 CFR Parts 20 and 72, it may be necessary to retitle the current term of "controlled area" in 10 CFR 60.2. The new title could be "postclosure-controlled area," which reflects the nature of the definition. The potential impact of this change in terminology will be minimized if done early. Therefore, it may be better to correct this ambiguity between 10 CFR Parts 20 and 60 sooner rather than later.

\subsubsection{Site and Site Boundary}

\section{Concept}

"Site boundary" means that location beyond which the land or property is not owned, leased, or otherwise controlled by the licensee.

\section{Discussion}

\section{CFR Part 60 Comparison}

10 CFR Part 60 currently defines the term "site" as the location of the controlled area. This definition may be in conflict with the definitions in 10 CFR Part 20 and 40 CFR Part 191, Subpart A. As a result, it may be unclear where NRC and EPA preclosure dose limits for the public are applicable. 10 CFR Part 20 defines the term "site boundary," which is used for limiting doses to the public during operations.

10 CFR Parts 20,60, 72 and 40 CFR Part 191 contain definitions for "site" or "site boundary." With the exception of 10 CFR Part 60, all the definitions are similar, in that they essentially depict the site as the real property owned or leased by the licensee. The differences noted are twofold: (i) there is a difference in the definition of a term, and (ii) there is a difference in concept. 


\section{Concept Comparison}

The Concept provides a definition of "site boundary" which is the same as the definition of "site boundary" in 10 CFR Part 20. This would make 10 CFR Part 60 consistent with 10 CFR Part 20.

\subsubsection{Elements Considered for Regulation}

\subsubsection{Design Bases and Design Basis Events}

\section{Elements Considered}

The elements considered in this subtopic are:

- Design Events I consist of those events that are expected to occur regularly or frequently in the course of normal operation (ANS, 1984)

- Design Events II consist of those of events that, although not occurring regularly, can be expected to occur with moderate frequency or on the order of once during a calendar year of operation (ANS, 1984)

- Design Events III consist of those infrequent events that could reasonably be expected to occur during the lifetime of the facility (ANS, 1984)

- Design Events IV consist of the credible events that are assumed to occur because their consequences may result in the maximum potential impact on the immediate environs. Typically this set of events will consist of plant-specific design events as defined in design phenomena. Design phenomena consist of those natural phenomena and human-induced low probability events for which an ISFSI is designed (ANS, 1984)

- A DBE would include Design Events I-IV.

\section{Discussion on Elements Considered}

The phrase "credible events and credible accidents" is used to help in identification of items important to safety, as discussed in Section 4.2 of NRC, 1988. This phrase is introduced to help guide the licensee in developing scenarios to calculate what potential exposures may occur for a given repository design. After a dose is calculated, then a determination could be made whether the process and its associated equipment and operations involved with the scenario would be important to safety. If the dose limit given in the current 10 CFR 60.2 definition of important to safety is exceeded the associated equipment would need to be placed on the "Q-List." The terms "credible events" and "credible accidents, " in Section 4.2 of NRC, 1988, seem to be used for identification of structures, systems, and components important to safety and not to define conditions and events that must be considered in designing structures, systems, and components important to safety to ensure their continued safety functions.

Definitions of design bases and DBEs that clarify the intent of Design Events I-IV, (ANS, 1984) could be added to 10 CFR Part 60 . This would clarify how preclosure performance objectives and design criteria for the GROA can be applied correctly.

Concerning a possible definition of "design bases," in 10 CFR Parts 50 and 72, two different terms are used in association with the design of structures, systems, and components important to safety. 
The definition of "design bases" in 10 CFR 50.2 uses the term "postulated accident" and 10 CFR 72.3 uses the term "postulated event," neither of which are defined. Also, the term "design basis events" is defined in 10 CFR 50.49(b)(1). 10 CFR Part 60 uses the term "design bases" in 10 CFR 60.21(c)(2)(ii), 60.73(b), 60.130, and 60.141(d) but does not link design bases to a design basis accident or DBE. 10 CFR Part 60 uses the term "design bases" in the sense that the licensee is to provide the bases (the foundation, principles, assumptions, or considerations) upon which the design and license specifications are established.

10 CFR 72.3 defines the term "design bases" as:

"Design bases" means that information that identifies the specific functions to be performed by a structure, system, or component of a facility and the specific values or ranges of values chosen for controlling parameters as reference bounds for design. These values may be restraints derived from generally accepted 'state-of-the-art' practices for achieving functional goals or requirements derived from analysis (based on calculation or experiments) of the effects of a postulated event under which a structure, system, or component must meet its functional goals. The values for controlling parameters for external events include: (i) estimates of severe natural events to be used for deriving design bases that will be based on consideration of historical data on the associated parameters, physical data, or analysis of upper limits of the physical processes involved and (ii) estimates of severe external man-induced events to be used for deriving design bases that will be based on analysis of human activity in the region taking into account the site characteristics and the risks associated with the event.

10 CFR 50.49(b)(1) states, "design basis events are defined as conditions of normal operation, including anticipated operational occurrences, design basis accidents, external events, and natural phenomena for which the plant must be designed to ensure functions (i) through (iii) of this paragraph."

Identifying a set of structures, systems, and components that are important to safety requires the development of design bases, as defined above. These design bases make it possible to determine which of the structures, systems, and components must perform particular safety functions in order to provide reasonable assurance that the storage and handling of spent fuel and radioactive waste present no undue risk to the health and safety of the public.

\subsubsection{Important to Safety}

\section{Elements Considered}

Elements to consider regarding what structures, systems and components are important to safety are:

- Equipment used for receiving HLW (e.g., hoists, cranes or other equipment used to lift or tilt a transport cask, shielding used during removal of waste from a transport cask, equipment used to remove the waste from the cask)

- Structures, equipment, or materials used to store HLW (e.g., storage bins, lag storage bins, supports for these bins, inert gas to prevent HLW corrosion, materials used to prevent criticality, necessary cooling equipment) 
- Facilities or components that directly contain or shield HLW (e.g., the waste package, a hot cell used for fuel rod consolidation, a shielded room where the HLW is transferred between containers, a sealed holding container for temporary storage)

- Equipment that transfers HLW (intra-facility movement of HLW) (e.g., equipment that moves waste from one storage location to another, hoist, cranes, rail-mounted cranes or hoists, rail cars, trucks, conveyor belts)

- Equipment that emplaces HLW (e.g., shielding guards, equipment that ensures waste package alignment, equipment that ensures a waste package is not stressed during emplacement)

- Features of HLW disposal impacting on or impacted by operations (e.g., a sealed emplacement location, shielding via a plug or seal, shielding via the rock mass, emplacement hole stabilizers that prevent or mitigate damage to the emplaced waste package location)

- Equipment used to handle HLW or waste package containers (e.g., rod consolidation equipment, direct contact inspection equipment, most of the equipment listed above)

- Equipment used to retrieve HLW (e.g., waste locating equipment, waste package removal equipment, waste transfer equipment for removal to the surface, retrieved waste storage, retrieved waste loading equipment)

- Personnel who operate the above equipment (e.g., HLW crane operators, emplacement machine operators, inspectors)

- Procedures used to operate the above equipment or facilities

- Maintenance of this equipment or facilities

\section{Discussion on Elements Considered}

The definition of the term "important to safety" needs to encompass the facilities, equipment, personnel, and procedures used to directly operate and maintain those features of a GROA that involve HLW, until the license is terminated. Those features of a GROA directly involved in assuring safety could include: receiving, handling, transporting (moving), storing, containing, emplacing, and retrieving waste, and safely keeping the waste in its emplaced location. Also, the definition needs to encompass the protection of and prevention of damage to the waste and waste package container. This is needed because features of the GROA that directly interact with the waste and waste package container may cause a radiation accident. The features of the GROA that are important to safety need to meet the more rigorous criteria for design and quality assurance as specified in 10 CFR 60.131(b), 60.151, and 60.160.

10 CFR Part 60 currently defines "important to safety" as:

"Important to safety," with reference to structures, systems, and components means those engineered structures, systems, and components essential to the prevention or mitigation of an accident that could result in a radiation dose to the whole body, or any organ, of $0.5 \mathrm{rem}$ $(5 \mathrm{mSv})$ or greater at or beyond the nearest boundary of the unrestricted area at any time until the completion of permanent closure.

Although the use of the term "accidents" might be subject to conjecture regarding its meaning, the major shortcoming of the language is that it links the class of structures, systems, and components important to safety to the size of the unrestricted area. By extending the boundary of the unrestricted area far enough from the GROA, one could in principle remove all structures, systems, and components from the design and quality assurance requirements specific to items important to safety. Another shortcoming 
is that the definition overlooks the need to protect onsite personnel (workers) in the event of accidents in a manner consistent with NRC defense-in-depth philosophy.

\subsubsection{Controlled Area or Controlled-use Area}

\section{Elements Considered}

Elements to be considered in establishing a controlled area or controlled-use area would include:

- An area which to which access can be controlled by the licensee

- An area sufficiently large to provide a measure of safety to the public, at the boundary of this area, in the event of a DBE resulting in a release of radioactive material

\section{Discussion on Elements Considered}

One of the elements of the defense-in-depth philosophy is to provide for the establishment of a controlled area or controlled-use area from which members of the public can be excluded if an accident should occur as the consequence of some DBE. The definition of a "controlled area" or "controlled-use area" should be included in 10 CFR Part 60 in order to reflect this philosophy.

10 CFR Part 72 contains a provision for protection to public health and safety even under the most unlikely credible conditions. As specified in 10 CFR 72.106, for each ISFSI or MRS site, there must be a controlled area of such size that no individual located on or beyond its boundary will receive a dose greater than 5 rems $(0.05 \mathrm{~Sv})$ to the whole body or any organ from a design basis accident. Both external natural events and external human-induced events must be considered in defining the design bases that would result in the design basis accident. This concept is consistent with the policy of striving to conduct operations so that under likely conditions both occupational and public exposure levels will cunform to 10 CFR Part 20, yet it recognizes that in some instances other measures should be employed to assure that adverse consequences are kept to acceptable levels.

Existing terminology in 10 CFR Part 60 differs from the language of 10 CFR Part 20 in several respects - notably with respect to the terms "controlled area" and "site" (or "site boundary"). A change to the rule may need to address the consistent use of several specific terminologies, in order to reduce any ambiguities.

\subsubsection{Postclosure-controlled Area}

\section{Elements Considered}

Elements to be considered in determining if the current definition of "controlled area" in 10 CFR Part 60 should be changed to "postclosure-controlled area" include:

- Definitions of similar areas, i.e., controlled area and exclusion area, in various regulations may need to be consistent

- Definition of "controlled area" in 10 CFR Part 60 applies to the postclosure phase of the Geologic Repository

- Other definitions, i.e., controlled area and exclusion area, apply to facilities where access can be controlled during operations 
- Impact of changing the defirition in 10 CFR Part 60 should be minimal

- Consistency with the revised EPA 40 CFR Part 191 should be provided

\section{Discussion on Elements Considered}

The current 10 CFR Part 60 definition of "controlled area" may need to be changed to a term such as "postclosure-controlled area." This would allow introducing a new definition of "controlled area," which is the same as 10 CFR Part 20. A new definition of a "controlled area" or "controlled-use area" could be added to 10 CFR 60.2 that has the same intent as the definition of a "controlled area" in 10 CFR 20.1003. Other requirements in 10 CFR Part 60 which currently use the term "controlled area" would require an editorial substitution of "postclosure-controlled area" for "controlled area." This would make 10 CFR Part 60 consistent with 10 CFR Part 20 and conceptually consistent with 10 CFR Part 72.

\subsubsection{Site and Site Boundary}

\section{Elements Considered}

Elements to be considered in determining whether the current definition of "site" in 10 CFR Part 60 should be replaced with the definition of "site boundary" in 10 CFR Part 20 include:

- Definitions of similar areas, i.e., site and site boundary, in various regulations may need to be consistent

- Definition of site or site boundary should refer to land owned or otherwise controlled by the licensee so that access can be controlled in the event of a DBE

- Impact of changing the definition in 10 CFR Part 60 should be minimal

Discussion on Elements Considered

10 CFR Part 60 currently defines the term "site" as the location of the controlled area. To make 10 CFR Parts 20 and 60 consistent, the definition of "site" in 10 CFR 60.2 may need to be made compatible with the term "site boundary" in 10 CFR 20.1003. In general, the term "site" is used in 10 CFR Part 60 in an easily understood context, especially when associated with site characterization. Where the term "site" is specifically intended to mean the controlled area it is also easily understood. Since a geologic repository has preclosure and postclosure phases that each have unique siting requirements the potential for conflicting use of terminology may be difficult to avoid.

\subsubsection{Safety Functions and Regulatory Citations}

\subsubsection{Safety Functions}

There are no safety functions (Romine, 1992) associated with terminology definitions

\subsubsection{Relevant Regulatory Citations}

- 10 CFR 20.1002 and 20.1003

- 10 CFR 50.2 and 50.49(b)(1) 
- 10 CFR 60.2, 60.21(c)(1)(i), 60.21(c)(1)(ii)(B), 60.21(c)(2)(ii), 60.21(c)(3), 60.21(c)(7), 60.21(c)(8), 60.43(b)(5), 60.46(a)(3), 60.51(a)(2), 60.73(b), 60.102(c), 60.121(a)(1), 60.121(b), 60.122(b)(6), 60.122(c), 60.122(c)(12), 60.122(c)(17), 60.122(c)(18), 60.122(c)(19), 60.130, 60.131(b), 60.141(d), 60.151, and 60.160

- 10 CFR 72.3 and 72.106

- 10 CFR 100.3

- 40 CFR Part 191, Subpart A

\subsection{RADIOLOGICAL EMERGENCY PLANNING}

This ROC Topic has the following subtopics:

(1) Definitions Relevant to Emergency Planning

(2) Emergency Plan Requirements

(3) Offsite Organization Comments

(4) Plan Review for Offsite Assistance

\subsubsection{Recommendations and Conclusions}

\subsubsection{Definitions Relevant to Emergency Planning}

\section{Recommendation}

Definitions for the terms "alert" and "site area emergency" may need to be added to 10 CFR Part 60 to make it consistent with other regulatory citations containing emergency planning criteria, i.e., 10 CFR 30.4, 40.4, and 70.4.

\section{Conclusions}

Definitions for the terms "alert" and "site area emergency" would be needed because these terms are introduced by the emergency planning criteria contained in other regulatory citations i.e., 10 CFR $30.4,40.4$, and 70.4 .

\subsubsection{Emergency Plan Requirements}

\section{Recommendation}

10 CFR Part 60.

Criteria which provide requirements for emergency planning should be added to Subpart I of

\section{Conclusions}

10 CFR Part 60, Subpart I is presently reserved. There is a need for regulatory criteria regarding emergency preparedness in this subpart. These criteria should include information regarding (i) facility organization for emergencies, (ii) types of radiation accidents, (iii) classification and notification of accidents, (iv) responsibilities, (v) activation of the response force, (vi) assessment of releases, (vii) mitigation of releases and response for recovery, (viii) detection of radiation accidents, (ix) 
medical evacuation or transportation, (x) medical facilities, (xi) communications and coordination, (xii) information and status reporting, and (xiii) training, planned exercises, and maintenance readiness. 10 CFR Part 30 permits the licensee the option to demonstrate that an emergency plan is not required. That approach is not suggested here because the intent of 10 CFR Part 60 is to have a Subpart I that deals with emergency planning criteria. The inclusion of these criteria in 10 CFR Part 60 will enhance emergency preparedness and provide defense-in-depth for the protection of worker and public health and safety.

\subsubsection{Orfsite Organization Comments}

\section{Recommendation}

Subpart I of 10 CFR Part 60 should provide criteria for the review of plans by offsite organizations that may be called upon for assistance.

\section{Conclusions}

10 CFR. Part 60, Subpart I is presently reserved. There is a need for regulatory criteria regarding offsice organization review of emergency plans.

\subsubsection{Plan Review for Offsite Assistance}

\section{Recommendation}

Subpart I of 10 CFR Part 60 should contain criteria for NRC review the adequacy of emergency plans for offsite assistance.

\section{Conclusions}

The inclusion of these criteria in Subpart I will ensure that emergency plans will be reviewed for adequacy and that these plans provide for the protection of worker and public health and safety.

\subsubsection{Concepts and Discussion}

\subsubsection{Definitions Relevant to Emergency Planning}

\section{Concept}

"Alert" means events may occur, are in progress, or have occurred that could lead to a release of radioactive material but that release is not expected to require a response by offsite response organizations to protect persons offsite.

"Site area emergency" means events may occur, are in progress, or have occurrad that lead to a significant release of radioactive material and that release could require a response by offsite response organizations to protect persons offsite. 


\section{Discussion}

\section{CFR Part 60 Comparison}

Subpart I, Emergency Planning Criteria, of 10 CFR Part 60 and 10 CFR 72.32(a) and 72.32(b) are reserved. 10 CFR 30.32(i)(3), 30.32(i)(4), 40.31(j)(3), 40.31(j)(4), 50.47, and 70.22(i), contain emergency planning criteria; and these regulatory criteria include terms that are defined and pertain to the classification of accidents.

\section{Concept Comparison}

The Concept above is comparable with other NRC regulations containing emergency planning criteria. However, the Concept is different from 10 CFR Part 60 because the emergency planning criteria is reserved.

\subsubsection{Emergency Plan Requirements}

\section{Concept}

Each application for a geologic repository that is licensed under 10 CFR Part 60 should be accompanied by an emergency plan that includes the following information.

- A description of the licensee's facility and area near the site

- An identification of each type of radioactive materials accident for which protective actions may be needed

- A classification system for classifying accidents as alerts or site area emergencies

- Identification of the means of detecting each type of accident in a timely manner

- A description of the means of mitigating the consequences of each type of accident, including those provided to protect workers onsite, and a description of the program for maintaining the equipment

- A description of the methods and equipment to assess releases of radioactive materials

- A description of the responsibilities of licensee personnel should an accident occur, including identification of personnel responsible for promptly notifying offsite response organizations and the NRC; also, responsibilities for developing, maintaining, and updating the plan

- A commitment to and a description of the means to promptly notify offsite response organizations and request offsite assistance, including medical assistance for the treatment of contaminated injuied onsite workers when appropriate. A control point must be established. The notification and coordination must be planned so that unavailability of some personnel, parts of the facility, and some equipment will not prevent the notification and coordination. The licensee shall also commit to notify the NRC operations center immediately after notification of the appropriate offsite response organizations and not later than one hour after the licensee declares an emergency ${ }^{1}$

1 These reporting requirements would not supersede or release licensees from complying with the requirements under the Emergency Planning and Community Right-To-Know Act (U.S. Congress, 1986) or other state or federal reporting requirements. 
- A description of the types of information on facility status, radioactive releases, and recommended protective actions, if necessary, to be given to offsite response organizations and the NRC

- A description of the training that the licensee will provide workers on how to respond to an emergency and any special instructions and orientation tours the licensee would offer to fire, police, medical and other emergency personnel

- A description of the means of restoring the facility to a safe condition after an accident

- A description of the provisions for conducting quarterly communications checks with offsite response organizations and annual onsite exercises to test response to simulated emergencies (Radiological/health physics, medical, and fire drills should be held semiannually. Quarterly communications checks with offsite response organizations must include the check and update of all necessary telephone numbers. The licensee should invite offsite response organizations to participate in the annual exercises. Participation of offsite response organizations in annual exercises although recommended is not required. The licensee should conduct exercises that use scenarios not known to most exercise participants. The licensee shall critique each exercise using individuals not having direct implementation responsibility for the plan. The licensee should critique the exercises to evaluate the appropriateness of the plan, emergency procedures, facilities, equipment, training of personnel, and overall effectiveness of the response. Deficiencies found by the critiques must be corrected.)

- A certification that the applicant has met its responsibilities under the Emergency Planning and Community Right-to-Know Act (U.S. Congress, 1986), if applicable to the applicant's activities at the proposed place of use of special nuclear material

- A description of arrangements made to provide information to the public

\section{Discussion}

\section{CFR Part 60 Comparison}

10 CFR Parts 30, 40, 50, and 70 all contain criteria for emergency planning, such as that listed above. 10 CFR Part 60 emergency planning criteria is reserved.

\section{Concept Comparison}

The Concept contains criteria for emergency plans which are consistent with other regulations containing emergency planning criteria, i.e., 10 CFR Parts 30, 40, 50, and 70.

\subsubsection{Offsite Organization Comments}

\section{Concept}

The licensee should allow the offsite response organizations expected to respond in case of an accident 60 days to comment on the licensee's emergency plan before submitting it to the NRC. The licensee should provide any comments received within the 60 days to the NRC with the emergency plan. 


\section{Discussion}

\section{CFR Part 60 Comparison}

10 CFR Parts 30, 40, 50, and 70 all contain criteria for emergency planning including the requirement for plans to be reviewed by offsite response organizations that may be called upon for assistance. 10 CFR Part 60 emergency planning criteria is reserved.

\section{Concept Comparison}

The Concept for emergency plans to be reviewed by offsite response organizations, that may be called upon for assistance, is consistent with the criteria contained in 10 CFR Parts 30, 40, 50, and 70. 10 CFR Part 60 emergency planning criteria is reserved.

\subsubsection{Plan Review for Offsite Assistance}

\section{Concept} following:

Review of the applicant's emergency plan for potential offsite assistance should include the

- Arrangements for requesting and effectively using offsite assistance onsite

- Arrangements to accommodate State and local staff at the licensee's near-site emergency facility

- Arrangements for other organizations capable of augmenting the planned onsite response

- Provisions for prompt communications among principal response organizations to offsite emergency personnel who would be responding onsite

- Provisions for adequate emergency facilities and equipment to support the emergency response onsite

- Provisions for adequate methods, systems, and equipment for assessing and monitoring actual or potential consequences of a radiological emergency condition

- Arrangements for medical services for contaminated and injured onsite individuals

- Provisions for radiological emergency response training for those offsite who may be called to assist in an emergency onsite

\section{Discussion}

\section{CFR Part 60 Comparison}

10 CFR Parts 30, 40, 50, and 70 all contain criteria for emergency planning, such as that listed above. However, there are no criteria regarding NRC findings for the review of these plans. 10 CFR Part 60 emergency planning criteria is reserved.

\section{Concept Comparison}

The Concept contains criteria for the NRC staff to review an emergency plan to determine that it addresses offsite assistance adequately. 10 CFR Parts 30, 40, 60, and 70 are generally silent in this 
regard. 10 CFR Part 50, has comparable criteria to that in the Concept regarding review of plans for offsite assistance.

\subsubsection{Elements Considered for Regulation}

\subsubsection{Definitions Relevant to Emergency Planning}

\section{Elements Considered}

Elements of definitions to be added to 10 CFR Part 60 would depend upon the language introduced in Subpart I. Unique terminology to be used in Subpart I may require definition.

\section{Discussion of Elements Considered}

Since 10 CFR Part 60 contains no criteria for emergency planning, it also contains no definitions relevant to that subject. When emergency planning criteria are added to 10 CFR Part 60 , any unique terms introduced by these criteria could require definition in 10 CFR 60.2 , so that the regulatory criteria are clear and unambiguous.

\subsubsection{Emergency Plan Requirements}

\section{Eleinents Considered}

Emergency plan requirements at a geologic repository should encompass:

- Establishment of an emergency response organization

- Delineation of responsibilities

- Establishment of emergency planning zones, if required

- Provision of adequate staffing for emergencies

- Provision of procedures for requesting assistance

- Development of emergency classifications

- Isolation of the source of the emergency

- Restoration of containment

- Decontamination of the area, to control radiation exposures

- Evacuation of personnel, i.e., worker and/or public

- Provision of adequate staffing for emergencies

- Provision of means to notify the affected populace and communications with State and local organizations and the media

- Provision of facilities and equipment to respond to emergencies, i.e., transport vehicles, communications, emergency supplies (air packs), escape routes, air monitoring equipment, equipment to support protective actions, etc.

- Provision of means to control radiation exposures, shielding, protective clothing and equipment

- Provision of medical services, i.e., whole body counting, iodine tablets, antibiotics, etc.

- Training of personnel for emergency exercises and drills

- Provisions of plans for recovery or reentry

- Isolation of the source of the emergency 
- Restoration of containment, i.e., correct the cause of the release, or reduce the severity through sealing, shielding, etc.

- Provision of means to reenter area to restore pre-emergency conditions (recovery)

- Notification of the local populace of hazardous materials on site

\section{Discussion of Elements Considered}

Emergency planning is mentioned in 10 CFR 60.21(c)(9). 10 CFR Part 60 Subpart I should contain criteria which address: (i) the establishment of an emergency response organization with sufficient staffing, (ii) the emergency response measures to be employed in the event of a radiation accident, (iii) the emergency response capabilities required in the event of a radiation accident, and (iv) emergency recovery or restoration of the facility (site) following a radiation accident. This information would provide a basis for planning emergency actions at the GROA, which would enhance the degree to which worker and public health and safety can be protected.

\subsubsection{Offsite Organization Comments}

\section{Elements Considered}

Elements to consider regarding the review comment of offsite organizations are as follows:

- Review of emergency plans by organizations that will be requested to provide assistance

- Review of emergency capabilities of organizations that will be requested to provide assistance

\section{Discussion of Elements Considered}

Any pian that includes the use of offsite organization assistance should be reviewed by that organization to ensure that services expected can be rendered by that organization.

\subsubsection{Review for Offsite Assistance}

\section{Elements Considered}

Elements to consider regarding the review of the adequacy of offsite assistance are as follows:

- Plans should demonstrate that arrangements for requesting and effectively using offsite assistance have been made

- Plans should demonstrate that provisions for prompt communications with offsite response organizations exist

- Plans should demonstrate that adequate emergency facilities and equipment are provided

- Plans should demonstrate that adequate methods, systems and equipment for assessing and monitoring radiological emergency conditions are available

- Plans should demonstrate that arrangements for medical services have been made

- Plans should demonstrate that emergency response training has been made available to offsite response organizations 


\section{Discussion of Elements Considered}

In determining compliance with emergency planning requirements, the NRC staff should have some guidance with respect to ensuring that arrangements for offsite assistance have been included in the emergency response plans.

\subsubsection{Safety Functions and Regulatory Citations}

\subsubsection{Safety Functions}

\section{Definitions Relevant to Emergency Planning}

There are no safety functions (Romine, 1992) associated with definitions.

\section{Emergency Plan Requirements}

The safety functions (Romine, 1992) are:

Trained and certified personnel for security and safeguards unsafe/emergency conditions - 2.20.4.1

Plan for emergency evacuation of workers and the public during waste preparation operations - 5.1.3

Stop releases at the source during waste preparation operations -5.16 .2 .1 [sic] (5.16.7.1)

Limit spread of contamination during waste preparation operations - 5.16.2.2 [sic] (5.16.7.2)

Decontaminate in event of release during waste preparation operations 5.16.2.3 [sic] (5.16.7.3)

Limit radiation level during waste preparation unsafe/emergency conditions 5.16.2.4 [sic] $(5.16 .7 .4)$

Implement worker evacuation plan as appropriate during waste preparation operations - 5.16.2.5 [sic] (5.16.7.5)

Reestablish control of radioactive material at the source in event of accidental release during waste preparation operations - 5.17.3.1

Limit spread of contamination in event of accidental release during waste preparation operations (if possible) - 5.17.3.2

Decontaminate in event of accidental release during waste preparation operations (if possible) - 5.17.3.3 
Implement worker/public evacuation plan as appropriate in event of accidental release during waste preparation operations - 5.17.3.4

Emergency lighting for waste preparation operations - 5.35.1.3.5

Equipment for response to waste disposal package components unsafe conditions - 5.35.2.2.6

Trained and certified personnel for response to waste disposal package component receiving unsafe conditions - 5.35.2.4.3

Procedure(s) for response to unsafe conditions during receiving operations - 5.35.2.5.3

Equipment for waste lag storage unsafe/emergency conditions - 5.35.3.2.6

Trained and certified personnel for waste lag storage unsafe/emergency conditions - 5.35.3.4.3

Procedure(s) for waste lag storage unsafe/emergency conditions $\mathbf{- 5 . 3 5 . 3 . 5 . 3}$

Equipment for response to waste disposal package components lag storage unsafe conditions - 5.35.4.2.5

Trained and certified personnel for response to waste disposal package components lag storage unsafe conditions - 5.35.4.4.4

Procedure(s) for response to waste disposal package components lag storage unsafe conditions - 5.35.4.5.4

Equipment for waste packaging unsafe/emergency conditions - 5.35.5.2.12

Trained and certified personnel for waste packaging unsafe/emergency conditions - 5.35.5.4.3

Procedure(s) for waste packaging unsafe/emergency conditions -5 .35.5.5.3

Plan for emergency evacuation during disposal operations - 6.1.4

Decontaminate in event of release dıring waste disposal operations - 6.16.2.3

Limit consequences of accidental $r$ dionuclide releases during waste disposal operations -6.17 .3$

Reestablish control of radioactive material at the source in event of accidental release - 6.17.3.1

Limit spread of contamination in event of accidental release (if possible) - 6.17.3.2

Decontaminate in event of accidental release (if possible) - 6.17.3.3

Implement worker/public evacuation plan as appropriate in event of accidental release - 6.17.3.4 Prevent nuclear criticality during waste disposal operations -6.19 
Personal air supply(ies) for underground emergencies - 6.41.1.2.1

Underground emergency escape/rescue routes and refuges - 6.41.1.2.2

Equipment for underground emergency escape/rescue - 6.41.1.2.3

Aqueous and non-aqueous underground fire protection facilities and equipment - 6.41.1.2.4

Uninterruptable power source(s) (e.g., for repository instrumentation, alarms, communications, and lighting important to safety) - 6.41.1.3.1.4

Emergency lighting for repository surface-subsurface common facilities - 6.41.1.3.1.5

Trained and certified personnel for repository waste receiving radiological unsafe/emergency conditions - 6.41.2.4.3

Repository equipment for waste lag storage radiological unsafe/emergency conditions - 6.41.3.2.6

Trained and certified personnel for repository waste lag storage radiological unsafe/emergency conditions during repository operations - 6.41.3.4.3

Procedure(s) for waste lag storage radiological unsafe/emergency conditions during repository operations - 6.41.3.5.3

Procedure(s) for waste transfer radiological unsafe/emergency conditions - 6.41.4.5.2

Procedure(s) for waste emplacement radiological unsafe/emergency conditions - 6.41.5.5.2

Equipment for monitoring and alarm during repository operations - 6.41.6.2

Equipment for waste removal radiological unsafe/emergency condition - 6.41.7.2.9

Trained and certified personnel for waste removal radiological unsafe/emergency conditions - 6.41.7.4.3

Procedure(s) for waste removal radiological unsafe/emergency conditions - 6.41.7.5.2

Equipment for radiological unsafe/emergency conditions in off-site shipment operations - 6.41.8.2.11

Procedure(s) for waste off-site shipment radiological unsafe/emergency conditions - 6.41.8.5.5

Equipment for closure and decommissioning radiological unsafe/emergency conditions - 6.41.9.2.11

Trained and certified personnel for closure and decommissioning radiological unsafe/emergency conditions - 6.41.9.4.10 
Procedure(s) for closure and decommissioning radiological unsafe/emergency conditions - 6.41.9.5.10

\section{Offsite Organization Comments}

The safety functions (Romine, 1992) are:

Plan for accident/emergency contingencies in waste preparation operations including any unforeseen loss or potential loss of containment within waste preparation facilities - 5.1.2

Plan for emergency evacuation of workers and the public during waste preparation operations - 5.1.3

Plan for emergency repository operations contingencies including unforeseen loss or potential loss of containment $-\mathbf{6 . 1 . 2}$

Plan for emergency evacuation during disposal operations - 6.1 .4

Plan Review for Orfsite Assistance

There are no safety functions (Romine, 1992) associated with emergency plan review.

\subsubsection{Relevant Regulatory Citations}

- 10 CFR 30.4, 30.32(i)(3), and 30.32(i)(4)

- 10 CFR 40.4, 40.31(j)(3), and 40.31(j)(4)

- 10 CFR 50.47

- 10 CFR 60.2, 60.21(c)(9), and Subpart I

- 10 CFR 70.4 and 70.22(i)

- 10 CFR 72.32(a) and 72.32(b) 


\section{SUMMARY}

The five ROC Topics investigated here generally recommend that the GROA be designed and sited to ensure defense-in-depth. This is accomplished by the GROA being designed to meet the necessary radiation control limits for Design Events I, II, and III (ANS, 1984). Also, items important to safety should be designed to perform their safety functions under Design Events IV (ANS, 1984). Finally, the GROA should be sited and radiological emergency plans prepared to assure public and worker health and safety in the unlikely event of a radiation accident, where the limits of 10 CFR Part 20 and the EPA standards are unexpectedly exceeded.

A summary of the specific recommendations and conclusions includes:

- The intent regarding the performance objectives for radiation safety may need to be clarified

- The intent of the performance of structures, systems, and components important to safety and the preclosure performance of the site may need to be clarified to assure defense-indepth

- Consistent terminology for the various classes of DBEs should be utilized

- It is clear that 10 CFR Part 60 regulates concentrations of airborne radioactive material in restricted and unrestricted areas and that design for decontamination is not limited to decommissioning only

- Design considerations for human-induced events may need to be clarified

- The meaning of the term "emergency" in relation to "radiation accidents" may need to be clarified

- Criteria may be needed for establishment of a controlled area or controlled-use area for the preclosure period of the GROA

- A criterion requiring analysis of the potential effect of any DBE may be needed

- Criteria for collective dose limits in 10 CFR Part 60 are premature

- Current 10 CFR Part 60 criteria for preclosure site assessment are adequate

- The terms "design bases", "DBE," "controlled area" or "controlled-use area", "postclosure restricted area," "site" and "site boundary" may need to be added to or changed within 10 CFR Part 60 or made consistent with other regulations

- Criteria and definitions related to radiological emergency planning need to be added to 10 CFR Part 60. 


\section{REFERENCES}

ANS. 1984. Design Criterla for an Independent Spent Fuel Storage Installation (Dry Storage Type). ANSI/ANS-57.9-1984. LaGrange Park, IL: ANS.

EPA. 1991. Manual of Protective Action Guides and Protective Actions for Nuclear Incidents. EPA-400-R-92-001. Washington, DC: EPA.

Hageman, J.P., and A.H. Chowdhury. 1992. Repository Operational Criteria Analysis. NUREG/CR-5804. CNWRA 91-014. Washington, DC: NRC.

NRC. 1983. Staff Analysis of Public Comments on Proposed Rule 10 CFR Part 60. Disposal of high-level radioactive wastes in geologic repositories. NUREG-0804. Washington, DC: NRC.

NRC. 1986. Proposed amendments to conform to EPA general environmental standards. Federal Register 51(109): 22288-22296. Washington, DC: NRC.

NRC. 1988. Technical Position on Items and Activities in the High-Level Waste Geologic Repository Program Subject to Quality Assurance Requirements. NUREG-1318. Washington, DC: NRC.

NRC. 1989. Standard Format and Content Guide for the Safety Analysis Report for an Independent Spent Fuel Storage Installation or Monitored Retrievable Storage Installation (Dry Storage). Regulatory Guide 3.48, Rev. 1. Washington, DC: NRC.

NRC. 1990. Performance objectives, relating to isolation of the waste. Federal Register 54(159): 33565-33566. Washington, DC: NRC.

NRC. 1991. Systematic regulatory analysis regulatory and institutional uncertainty reduction recommendations. Task Team Report. Washington, DC: NRC.

Romine, D.T. 1992. High-Level Radioactive Waste Repository Functional Analysis. CNWRA 91-001. San Antonio, TX: CNWRA.

U.S. Congress. 1986. Emergency Planning and Community Right-to-Know Act of 1986. Pub. L. 99-499. 42 Stat. 11001. Washington, DC: U.S. Congress.

Weiner, R.F., W.C. Patrick, and D.T. Romine. 1990. Identification and Evaluation of Regulatory and Institutional Uncertainties in 10 CFR Part 60. CNWRA 90-003. San Antonio, TX: CNWRA. 

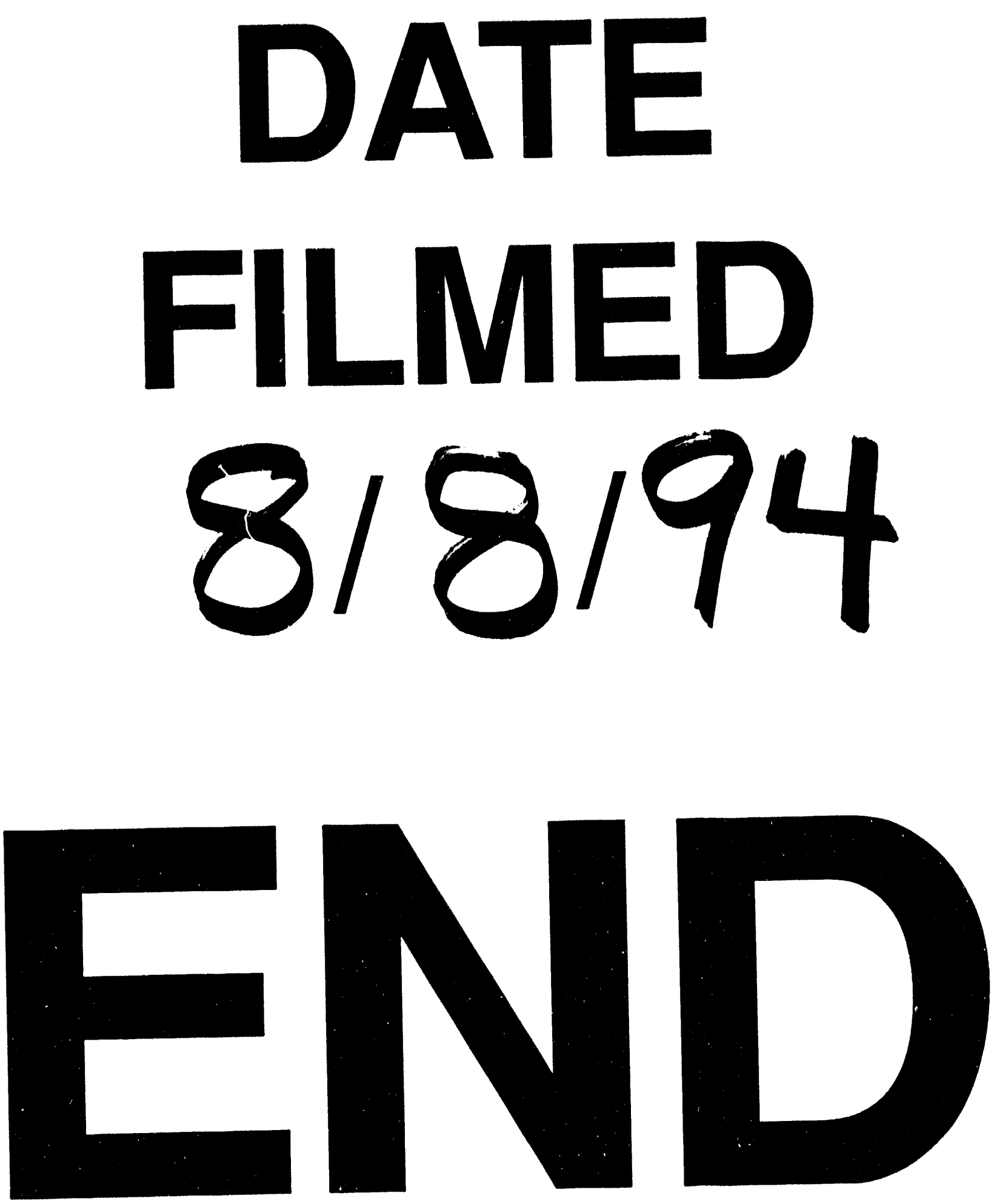
